\title{
High-level Ab Initio Studies of Hydrogen Abstraction from Prototype Hydrocarbon Systems
}

\author{
Berhane Temelso, ${ }^{a}$ C. David Sherrill, ${ }^{a *}$ \\ Ralph C. Merkle, ${ }^{b *}$ and Robert A. Freitas Jr. ${ }^{c *}$ \\ ${ }^{a}$ Center for Computational Molecular Science and Technology, \\ School of Chemistry and Biochemistry, Georgia Institute of Technology, \\ Atlanta, GA 30332-0400 \\ ${ }^{b}$ College of Computing, Georgia Institute of Technology, \\ Atlanta, GA 30332-0280 \\ ${ }^{c}$ Institute for Molecular Manufacturing \\ 555 Bryant Street Ste. 354, \\ Palo Alto, CA 94301
}

July 19, 2006

\begin{abstract}
Symmetric and non-symmetric hydrogen abstraction reactions are studied using stateof-the-art $a b$ initio electronic structure methods. Second-order Møller-Plesset perturbation theory (MP2) and the coupled-cluster singles, doubles and perturbative triples [CCSD(T)] methods with large correlation consistent basis sets (cc-pVXZ, where $\mathrm{X}=\mathrm{D}, \mathrm{T}, \mathrm{Q}$ ) are used in determining the transition-state geometries, activation barriers, and thermodynamic properties of several representative hydrogen abstraction reactions. The importance of basis set, electron correlation, and choice of zeroth-order reference wavefunction in the accurate prediction of activation barriers and reaction enthalpies are also investigated. The ethynyl radical $(\cdot \mathrm{CCH})$, which has a very high affinity for hydrogen atoms, is studied as a prototype hydrogen abstraction agent. Our high-level quantum mechanical computations indicate that hydrogen abstraction using the ethynyl radical has an activation energy of less than $3 \mathrm{kcal} \mathrm{mol}^{-1}$ for
\end{abstract}

*To whom correspondence should be addressed. E-mail addresses: sherrill@gatech.edu; merkle@cc.gatech.edu; rfreitas@rfreitas.com 
hydrogens bonded to an $s p^{2}$ or $s p^{3}$ carbon. These low activation barriers further corroborate previous studies suggesting that ethynyl-type radicals would make good tooltips for abstracting hydrogens from diamondoid surfaces during mechanosynthesis. Modeling the diamond $\mathrm{C}(111)$ surface with isobutane and treating the ethynyl radical as a tooltip, hydrogen abstraction in this reaction is predicted to be barrierless.

\section{Introduction}

Hydrogen transfer and abstraction reactions are ubiquitous, occurring in such diverse environments as enzymatic reactions, ${ }^{1}$ DNA strand breaking, ${ }^{2}$ catalysis, ${ }^{3}$ and all facets of organic chemistry. They also play a critical role in the making of diamond films via low-pressure chemical vapor deposition ${ }^{4}$ (CVD). The artificial synthesis of diamond, whether by CVD or other techniques such as high-temperature high-pressure ${ }^{5}$ (HTHP) crystallization of metal-solvated carbon, has attracted increasing interest in recent years. It is hoped that more economical ways to obtain diamond may unlock its scientific and technological potential, as it has many possible applications resulting from its unparalleled hardness, thermal and electrical conductivity, transparency in large regions of the electromagnetic spectrum, and wide band gap. In the CVD synthesis of diamond, a precursor hydrocarbon gas like methane enters a plasma/thermal/electric activation chamber in excess hydrogen gas. The activation process leads to the formation of atomic hydrogen, which abstracts hydrogen from the gas-phase hydrocarbons to yield very reactive carbon-containing radicals. These radicals deposit on the substrate and form carbon-carbon bonds leading to diamond growth. Atomic hydrogens also abstract hydrogen from the diamond surface, thereby creating nucleation sites for further diamond growth. They promote the preferential growth of diamond over graphite by etching graphite at a higher rate than diamond. This process, however, is guided by random diffusion of hydrocarbon radicals onto a substrate and subsequent hydrogen abstraction and donation reactions. The randomness in diamond CVD leads to the introduction of impurities and crystal lattice deformities that degrade the quality of the diamond films.

Some shortcomings of CVD have prompted the discussion of new approaches for diamond synthesis which might provide more control over the deposition of carbon-rich precursor molecules as well as the hydrogen abstraction/donation reactions. Mechanosynthesis is one new paradigm which proposes to attach a molecular tooltip to a scanning probe microscope (SPM) to perform elementary synthetic operations such as carbon deposition or hydrogen abstraction/donation at a specific location on the substrate. ${ }^{6-15}$ Such an approach has already been demonstrated theoretically and experimentally for the abstraction of hydrogen from a $\mathrm{Si}(100)$ surface and the selective manipulation of silicon atoms. ${ }^{16}$ Ethynyl radical has been suggested as a hydrogen abstraction tool because it can easily and rapidly abstract hydrogens from most hydrocarbons. ${ }^{6,17-19}$ To explore the feasibility of mechanosynthesis of diamond, an understanding of the thermochemistry and kinetics involved in the elementary processes becomes imperative, and modern theoretical methods are very useful in this endeavor.

Quantum chemical methods are capable of providing very accurate estimates of reaction thermodynamics. Indeed, the so-called Gaussian-1 (G1), ${ }^{20}$ Gaussian-2 (G2) ${ }^{21,22}$ and Gaussian3 (G3) $)^{23-25}$ composite methods and their variants are capable of providing reaction enthalpies 
typically within 1-2 $\mathrm{kcal} \mathrm{mol}^{-1}$ of experiment. These $\mathrm{G} n$ approaches combine a series of lowerlevel quantum computations to estimate the result of high-level correlated computations; the final values are then adjusted by additional empirical corrections. The similar Weizmann-1 (W1) and Weizmann-2 (W2) theories ${ }^{26}$ achieve comparable accuracies with only one molecule-independent empirical parameter, while the newer W3 formalism promises to provide accuracies in the order of $0.2 \mathrm{kcal} \mathrm{mol}^{-1}$ at a reasonable computational cost for small systems. ${ }^{27}$ Alternatively, the recent HEAT (high accuracy extrapolated ab initio thermochemistry) ${ }^{28}$ method provides similar accuracy in several test cases while avoiding any empirical corrections. Although these theoretical approaches are rather expensive computationally and applicable only to small molecular systems, they demonstrate that truly high-quality energetics are possible using modern $a b$ initio methods.

Several theoretical studies have examined hydrogen transfer reactions between small alkanes. Truhlar and co-workers have presented a comprehensive study of bond energies and classical activation barriers using semi-classical and semi-empirical methods. ${ }^{29}$ In other work considering purely $a b$ initio methods, they examined the challenges presented by radical-molecule reactions due to spin contamination and electron correlation in different methods. ${ }^{30}$ Litwinowicz et $a l .{ }^{31}$ evaluated the role of tunneling in simple hydrogen transfer reactions and also used spin projection techniques to remove spin contaminants and compare the resulting activation barriers with experimental values. Skokov and Wheeler and co-workers ${ }^{32}$ performed a similar study using density functional theory (DFT). Significant work to reconcile experimentally observed rates ${ }^{33,34}$ with theoretical values for the reactions of ethynyl radical with other small molecules has been done by Nguyen and co-workers. ${ }^{35-37}$

While numerous experimental and theoretical databases exist for the computation of heats of formation of simple hydrogen abstraction reactions, systematic and comprehensive high-accuracy studies of the reaction barriers (especially for reactions involving the ethynyl radical) are rare. Hence, a goal of the present work is to provide reliable benchmark activation barriers for such reactions. Here we consider several hydrogen abstraction reactions for simple hydrocarbons, focusing primarily on the ethynyl radical as the abstraction agent. Of particular interest is the reaction in which ethynyl radical abstracts hydrogen from isobutane, which serves as a good model ${ }^{38}$ of the diamond(111) surface. This model may shed light on the thermodynamic and kinetic feasibility of the hydrogen abstraction step in the mechanosynthesis of diamond. ${ }^{11-14,39,40}$

\section{Theoretical Methodology}

The symmetric hydrogen abstraction/transfer reactions considered in this study are given in reactions (1)-(3), along with the point-group symmetry considered for the reaction (and the corresponding Abelian computational subgroup).

$$
\begin{array}{cc}
\mathrm{H} \cdot+\mathrm{H}_{2} \rightarrow \mathrm{H}_{2}+\cdot \mathrm{H} & D_{\infty h} / D_{2 h} \\
\mathrm{CH}_{3} \cdot+\mathrm{CH}_{4} \rightarrow \mathrm{CH}_{4}+\cdot \mathrm{CH}_{3} & D_{3 d} / C_{2 h} \\
\mathrm{HCC} \cdot+\mathrm{HCCH} \rightarrow \mathrm{HCCH}+\cdot \mathrm{CCH} & D_{\infty h} / D_{2 h}
\end{array}
$$


The non-symmetric reactions considered are those in (4)-(8).

$$
\begin{aligned}
& \mathrm{HCC} \cdot+\mathrm{H}_{2} \rightarrow \mathrm{HCCH}+\cdot \mathrm{H} \quad C_{\infty v} / C_{2 v} \\
& \mathrm{HCC} \cdot+\mathrm{CH}_{4} \rightarrow \mathrm{HCCH}+\cdot \mathrm{CH}_{3} \quad C_{3 v} / C_{s} \\
& \mathrm{HCC} \cdot+\mathrm{C}_{2} \mathrm{H}_{4} \rightarrow \mathrm{HCCH}+\cdot \mathrm{C}_{2} \mathrm{H}_{3} \quad C_{s} / C_{s} \\
& \mathrm{HCC} \cdot+\mathrm{HC}\left(\mathrm{CH}_{3}\right)_{3} \rightarrow \mathrm{HCCH}+\cdot \mathrm{C}\left(\mathrm{CH}_{3}\right)_{3} \quad C_{3 v} / C_{s} \\
& \mathrm{HCC} \cdot+\mathrm{C}_{6} \mathrm{H}_{6} \rightarrow \mathrm{HCCH}+\cdot \mathrm{C}_{6} \mathrm{H}_{5} \quad C_{2 v} / C_{2 v}
\end{aligned}
$$

These systems are studied using Dunning's correlation consistent basis sets (cc-pVXZ, X=D,T,Q), ${ }^{41,42}$ which provide a systematic convergence of energies and properties toward the complete basis set (CBS) limit. For the sake of brevity, we will occasionally refer to these basis sets simply as DZ, TZ, and QZ in the tables. Electron correlation is accounted for using second-order Møller-Plesset perturbation theory (MP2) and coupled-cluster theory with single, double, and perturbative triple substitutions $[\mathrm{CCSD}(\mathrm{T})] .^{43}$

In order to gauge the reliability of density-functional methods for hydrogen abstraction reactions, we also employed the B3LYP ${ }^{44}$ and $\mathrm{BHLYP}^{45}$ (also called BH\&HLYP) functionals as implemented in MOLPRO. ${ }^{46}$ As discussed below, we found that the B3LYP/cc-pVDZ level of theory incorrectly predicts a bent geometry for the ground state of the ethynyl radical (although this is corrected with the larger cc-pVTZ basis) and it also gives unusually low barriers to the hydrogen abstraction reactions studied. Similar problems have also been observed for larger alkylethynyl radicals, but the use of hybrid functionals containing more Hartree-Fock (HF) exchange gives linear geometries for these radicals and more accurate abstraction barriers. ${ }^{47,48}$ One such functional is BHLYP ${ }^{45}$ which uses 50\% Hartree-Fock exchange (compared to $20 \%$ in B3LYP) and $50 \%$ Becke88 exchange ${ }^{49}$ in conjunction with the LYP correlation functional. ${ }^{50}$ (Of the many other exchange-correlation functionals designed to predict improved hydrogen abstraction barriers, the MPW1K $\mathrm{K}^{51}$ functional has had some success. $)^{35}$

For open-shell systems, we have considered both unrestricted and restricted open-shell orbitals. We will denote computations using unrestricted orbitals with a ' $U$ ' prefix, and those using restricted orbitals with an 'R' prefix (e.g., UMP2 or RMP2). Unrestricted orbitals are frequently easier to converge, and the extra flexibility they provide often improves results for bond-breaking and bond-making reactions when electronic near-degeneracy effects are strong. On the other hand, unrestricted orbitals can lead to poorer results in less severe cases of electronic near-degeneracies (e.g., in the spin-recoupling region of unimolecular dissociation reactions). ${ }^{52-55}$ Additionally, the use of unrestricted orbitals means that the wavefunction is no longer an eigenfunction of the $\hat{S}^{2}$ operator, and is contaminated by states with higher spin multiplicities. A comparison of restricted and unrestricted orbitals and a discussion of spin contamination are presented below. 
All DFT computations employed the MOLPRO 2002.6 program. ${ }^{46}$ UMP2 and UCCSD(T) computations were performed using ACES II. ${ }^{56}$ Open-shell RMP2 $2^{57}$ and RCCSD $(\mathrm{T})^{58,59} \mathrm{compu}-$ tations using restricted orbitals were performed using MOLPRO. Optimizations, transition state searches, and vibrational frequency analyses were performed using analytic energy gradients as implemented in ACES II. For MOLPRO 2002, which generally lacks analytic gradients, energies were differentiated numerically; this numerical differentiation process occasionally caused translational or rotational degrees of freedom to have frequencies deviating slightly from zero (values were real or imaginary and less than $50 \mathrm{~cm}^{-1}$ in magnitude). Although tightening the convergence criteria should remove these difficulties in principle, in practice we found that even tight convergence $\left(10^{-12}\right.$ on energies and $10^{-5}$ on gradients) had little effect due to limitations in the 2002 version of the program we used. We therefore attempted to identify and suppress these numerical artifacts in our subsequent analysis.

Because electronic near-degeneracies may become important as bonds are formed or broken, ${ }^{60-62}$ we performed full configuration interaction (full CI) computations for selected reactions to determine the effect of higher-order electron correlations beyond those included in the $\operatorname{CCSD}(\mathrm{T})$ method. For a given basis set, full CI includes a complete treatment of all many-body electron correlation effects, as it yields the exact solution to the time-independent, non-relativistic Schrödinger equation within the space spanned by the one-particle orbital basis set. Full CI computations were performed using the DETCI module ${ }^{63}$ of the PSI 3.2 package. ${ }^{64}$ The equation-of-motion (EOM) $\mathrm{CCSD}^{65}$ bending potentials for ethynyl radical were also generated using PSI $3.2,{ }^{64}$ while all other EOM-CCSD excitation energies were computed with ACES II. ${ }^{56}$

Experimental enthalpies of formation $\Delta H_{f}^{o}(298 \mathrm{~K})$ for our reactants and products are readily available ${ }^{66}$ and they entail relatively small uncertainties. These values have been used to obtain heats of reaction, $\Delta H(298 \mathrm{~K})$, for the reactions considered. In order to compare more directly with the experimental thermochemical data, we have converted our ab initio bare energy differences, $\Delta E$, into $0 \mathrm{~K}$ enthalpy differences, $\Delta H(0 \mathrm{~K})$, by adding the zero-point vibrational energy correction $(\triangle \mathrm{ZPVE})$, estimated simply as one-half of the sum of the (unscaled) vibrational frequencies. We also obtain $298 \mathrm{~K}$ enthalpy differences, $\Delta H(298 \mathrm{~K})$, by adding finite temperature corrections using the usual vibrational, rotational, and translational partition functions in conjunction with the harmonic oscillator, rigid rotator, and particle-in-a-box models.

The phenomenological activation barriers, $E_{a}$, are determined from experiment by an indirect process in which the reaction rate, $k$, is obtained at a series of temperatures, $T$. Fitting the temperature-dependent rate to a simple Arrhenius form, $k(T)=A e^{-E_{a} / R T}$, the physical activation barrier can be determined. The problem with this approach is that most rate-vs-temperature relations do not fit the Arrhenius form for all temperature regimes due to effects like hydrogen tunneling and the strong temperature dependence of the vibrational partition function when there are low-frequency bending modes, and these phenomena have been observed for most hydrogen abstraction reactions using the ethynyl radical. ${ }^{67}$ We used experimental activation barriers obtained from rate-vs-temperature data over a temperature range of about $150 \mathrm{~K}$ - $350 \mathrm{~K}$ for which the simple Arrhenius form was suitable and for which reaction rates were available. ${ }^{35,36,68-72}$ It must be stressed that these experimentally deduced activation barriers depend on the temperature range used for the Arrhenius fit, ${ }^{70}$ and that this complicates a direct comparison with reaction 
barriers computed quantum mechanically.

To compare our "classical" activation barriers, $\Delta E^{\ddagger}$, with these experimentally deduced activation energies, $E_{a}$, we first add zero-point vibrational corrections and finite-temperature corrections (as discussed above) to obtain $\Delta H^{\ddagger}(T)$. Next, it follows from transition state theory ${ }^{73}$ that for a reaction which undergoes a change of $\Delta n^{\ddagger}$ in the number of molecules while going from reactants to a transition state, the experimental $E_{a}(T)$ is related to $\Delta H^{\ddagger}(\mathrm{T})$ by

$$
E_{a}(T)=\Delta H^{\ddagger}(T)+\left(1-\Delta n^{\ddagger}\right) R T .
$$

$\Delta n^{\ddagger}$ for these bimolecular hydrogen abstraction reactions is -1 since the two reactants form one complex in the transition state.

One possible cause for a deviation from Arrhenius behavior is quantum mechanical tunneling of hydrogen atoms through classical barriers. The simplest approach to assess the role of quantum tunneling is the Wigner correction to the reaction rate. ${ }^{74,75}$ Given the magnitude $\nu_{t}$ of the imaginary frequency along the reaction coordinate at the transition state, the rate is enhanced by a factor of

$$
K_{W}(T)=1+\frac{1}{24}\left(\frac{h \nu_{t}}{k_{b} T}\right)^{2} .
$$

Note that this correction predicts tunneling to be faster through thin barriers (with large $\nu_{t}$ ) than through wide barriers (small $\nu_{t}$ ), as one would expect. Because we are comparing activation energies rather than rates, we may incorporate this correction into our theoretical results as an effective barrier height lowering by evaluating

$$
\Delta E_{a}=-k_{b} \frac{d \ln K_{W}}{d(1 / T)}=-2 k_{b} T \frac{y(T)}{1+y(T)},
$$

where $y(T)=\frac{1}{24}\left(h \nu_{t} / k_{b} T\right)^{2}$. As discussed below, this correction amounts to a few tenths of one $\mathrm{kcal} \mathrm{mol}{ }^{-1}$ for the systems studied. Wigner-corrected activation energies will be denoted $E_{a}-\mathrm{W}$.

\section{Results and Discussion}

\subsection{Transition State Geometries}

Vibrational normal mode analyses were performed to determine whether optimized structures corresponded to minima, transition states, or higher-order saddle points. For simplicity and for easier comparison among different levels of theory, only direct collinear $\mathrm{C}-\mathrm{H}-\mathrm{C}$ reaction coordinates were considered and symmetries were constrained as given in reactions (1)-(8). However, for some reactions at certain levels of theory, the true transition state (having exactly one imaginary vibrational frequency) may occur for lower-symmetry geometries than those considered. Table 1 reports those cases where the nominal (symmetry-constrained) transition states have a Hessian index (number of imaginary vibrational frequencies) greater than one. In these cases, the smaller additional imaginary frequencies correspond primarily to bending motions of the ethynyl radical 
(in some cases symmetry requires this bend to be doubly-degenerate). The CCH bends may be weakly coupled to rotation-like motions of the other reactant. For example, in the case of HCC. $+\mathrm{C}_{2} \mathrm{H}_{4}$, there are actually three extra imaginary frequencies at the RMP2/cc-pVDZ level of theory: one in-plane $\mathrm{CCH}$ bend and two out-of-plane vibrations corresponding to symmetric and antisymmetric combinations of the $\mathrm{CCH}$ bend coupled with a rotation of $\mathrm{C}_{2} \mathrm{H}_{4}$ relative to the $\mathrm{CCH}$.

For the reactions $\mathrm{HCC} \cdot+\mathrm{H}_{2} \rightarrow \mathrm{HCCH}+\cdot \mathrm{H}$ and $\mathrm{HCC} \cdot+\mathrm{HCCH} \rightarrow \mathrm{HCCH}+\cdot \mathrm{CCH}$, these extra imaginary frequencies appear to be artifactual because they tend to disappear upon using a larger basis set or a more robust level of theory. For reactions of ethynyl with $\mathrm{CH}_{4}, \mathrm{C}_{2} \mathrm{H}_{4}$, $\left(\mathrm{CH}_{3}\right)_{3} \mathrm{CH}$, and $\mathrm{C}_{6} \mathrm{H}_{5}$, the lower symmetry and/or larger size of the system made it difficult to pursue vibrational frequency analysis with the larger cc-pVTZ basis or the more reliable CCSD(T) method, and we were not always able to obtain these data. In these cases, it is not clear whether the extra imaginary frequencies are artifactual or not. However, given that they may indeed be artifactual, and also to ease comparisons among different levels of theory, we did not pursue computationally expensive transition state searches in lower symmetries, and any extra imaginary frequencies were ignored in subsequent analysis. In cases where the Hessian index was found to be greater than one, this means that our computed classical barrier $\Delta E^{\ddagger}$ will be an upper bound for that level of theory. For the reaction $\mathrm{HCC} \cdot+\mathrm{H}_{2} \rightarrow \mathrm{HCCH}+\cdot \mathrm{H}$ only, at the RMP2/cc-pVDZ level of theory, we followed one of the degenerate $80 \mathrm{i}$ frequencies downhill to a bent transition state which lies $0.4 \mathrm{kcal} \mathrm{mol}^{-1}$ lower in energy, giving a classical barrier $\Delta E^{\ddagger}$ of 2.8 instead of 3.2 $\mathrm{kcal} \mathrm{mol}^{-1}$. We expect that lower-symmetry transition state searches in other cases would yield similarly small energy lowerings but would not significantly affect our analysis (indeed, for our purposes, it would only complicate comparisons between different levels of theory).

Most of the non-symmetric reactions have very small activation barriers and large negative enthalpies of reaction (see below), so Hammond's postulate ${ }^{76}$ would suggest an "early" transition state with a geometry similar to that of the reactants. Our theoretical results in Table 2 for the cc-pVDZ basis set support this prediction. Using the MP2 or CCSD(T) methods, non-symmetric reactions feature a transition state geometry with only a modest $(0.03-0.06 \AA)$ stretch in the breaking bond and a fairly long distance (1.6-2.3 $\AA$ ) for the forming bond. The symmetric reactions, on the other hand, are expected to feature symmetric transition states with equal bond lengths for the forming and breaking bonds. This is what is observed except for the RMP2 method, where non-symmetric transition states are discovered. Figure 1 displays a contour diagram of the potential energy surface for $\mathrm{H} \cdot+\mathrm{H}_{2} \rightarrow \mathrm{H}_{2}+\mathrm{H} \cdot$ at the RMP2/cc-pVDZ level of theory. The surface features a shallow local minimum at symmetric geometries, with two symmetry-equivalent, nonsymmetric transition states on either side. We view this curious result as purely artifactual, and we note that ROHF references have led to other cases of unphysical results in the literature, including the classic example of the allyl radical. ${ }^{77,78}$ The more robust $\operatorname{CCSD}(\mathrm{T})$ method yields symmetric transition states for ROHF orbitals.

Except for the anomalous asymmetric transition states predicted by RMP2, the transition state geometries for the symmetric reactions are fairly similar (within $0.02 \AA$ for bonds to the abstracted hydrogen) no matter which theoretical method is used. Computed transition state geometries for the non-symmetric reactions, however, differ significantly depending on the theoretical method 
and whether restricted or unrestricted orbitals are used, except for $\operatorname{CCSD}(\mathrm{T})$, which is generally insensitive to the choice of orbitals. UB3LYP and RB3LYP, which suffer from significant selfinteraction errors at non-equilibrium geometries, yield geometries that greatly differ from the other theoretical estimates. Overall, the results from Table 2 underscore the need to exercise caution in choosing theoretical methods to study bond-breaking reactions, and they indicate that the robust CCSD(T) method appears (not surprisingly) to be the most reliable of those considered here for computing accurate transition state geometries of hydrogen abstraction reactions. Of course even $\operatorname{CCSD}(\mathrm{T})$ may break down for more difficult bond-breaking reactions, ${ }^{60}$ and the effect of electron correlation beyond $\mathrm{CCSD}(\mathrm{T})$ is explored below.

\subsection{Symmetric Reactions}

Barrier heights for the symmetric hydrogen transfer reactions are presented in Table 3 for several theoretical methods and basis sets. Basis set effects are fairly small for MP2 and CCSD(T), with barrier heights typically decreasing by a few tenths of one $\mathrm{kcal} \mathrm{mol}^{-1}$ upon improvement of the basis set. UMP2 results for $\mathrm{HCC}+\mathrm{HCCH}$ are out of line with this general trend and show a larger basis set effect of $\sim 3 \mathrm{kcal} \mathrm{mol}^{-1}$. Surprisingly, basis set effects in the symmetric reactions are larger for DFT, which is typically rather insensitive to basis set improvements. In contrast to the $a b$ initio results, the DFT barriers tend to increase as larger basis sets are used.

Comparing the theoretical methods to each other, we see that UMP2 significantly overestimates barrier heights, and UB3LYP and UBHLYP significantly underestimate them, compared to the more reliable $\mathrm{UCCSD}(\mathrm{T})$ results; the differences are several kcal mol ${ }^{-1}$. The difference among theoretical predictions is particularly surprising for the reaction $\mathrm{H}_{2}+\cdot \mathrm{H} \rightarrow \mathrm{H} \cdot+\mathrm{H}_{2}$, given that this is only a three-electron system. Large basis set UCCSD(T) computations should be nearly exact for this problem (see comparison to full CI below), and they yield values for $\Delta E^{\ddagger}$ around 10 $\mathrm{kcal} \mathrm{mol}^{-1}$. The UMP2 values, on the other hand, are around $13 \mathrm{kcal} \mathrm{mol}^{-1}$, while UB3LYP/ccpVQZ and UBHLYP/cc-pVQZ predict a mere $4.1 \mathrm{kcal} \mathrm{mol}^{-1}$ and $6.5 \mathrm{kcal} \mathrm{mol}^{-1}$, respectively. New density functionals that are designed to predict better hydrogen abstraction barriers do improve on B3LYP at least. In a study by Truhlar and co-workers, ${ }^{51}$ two such functionals MPW1K and MPW1PW91, using the $6-31+\mathrm{G}(\mathrm{d}, \mathrm{p})$ basis set, predict $\Delta E^{\ddagger}$ of 7.2 and $5.9 \mathrm{kcal} \mathrm{mol}^{-1}$, respectively.

For the reaction $\mathrm{HCC} \cdot+\mathrm{HCCH} \rightarrow \mathrm{HCCH}+\cdot \mathrm{CCH}$, in the cc-pVDZ basis, UMP2 overestimates and UB3LYP underestimates the UCCSD(T) classical barrier $\Delta E^{\ddagger}$ by as much as 7 and $5 \mathrm{kcal}$ $\mathrm{mol}^{-1}$, respectively. On the other hand, these UMP2 and UB3LYP errors become significantly smaller (5.3 and $0.4 \mathrm{kcal} \mathrm{mol}^{-1}$, respectively) in the cc-pVTZ basis set. Our UCCSD(T)/cc-pVTZ value of $11.7 \mathrm{kcal} \mathrm{mol}^{-1}$ for $\Delta E^{\ddagger}(0)$ compares well with the result of 12.1 obtained by Nguyen and co-workers $^{35}$ using at the MPW1K/6-311++G(3df,2p)//MPW1K/6-311++G(d,p) level of theory. On the other hand, there is a somewhat larger discrepancy than one might expect with Nguyen's result $^{37}$ of $13.9 \mathrm{kcal} \mathrm{mol}^{-1}$ at the $\operatorname{CCSD}(\mathrm{T})-\mathrm{fc} / 6-311++\mathrm{G}(\mathrm{d}, \mathrm{p}) / / \mathrm{B} 3 \mathrm{LYP} / 6-311++\mathrm{G}(\mathrm{d}, \mathrm{p})$ level of theory. Our preliminary investigations suggest that around half of this difference arises because Nguyen frozen core electrons, whereas we correlated all electrons because some of our computations employed software without frozen-core gradient capabilities; it is generally preferable to freeze core electrons when possible in studies using basis sets like cc-pVTZ, which lack core correlating functions. This frozen core effect appears to be larger than one might have expected, and indeed 
our exploratory computations indicate it is significantly smaller (a few tenths of one $\mathrm{kcal} \mathrm{mol}^{-1}$ ) for other reactions and levels of theory considered here. The remaining difference is between our value and Nguyen's is likely due to the differences in the basis set and small differences in geometries. Compared to the reactions of $\mathrm{H}_{2}+\cdot \mathrm{H}$ or $\mathrm{HCC} \cdot+\mathrm{HCCH}$, discrepancies between theoretical results are much less pronounced for $\mathrm{CH}_{4}+\cdot \mathrm{CH}_{3}$, on the order of $1-2 \mathrm{kcal} \mathrm{mol}^{-1}$ for the triple- $\zeta$ basis set [although the UB3LYP value remains $4 \mathrm{kcal} \mathrm{mol}^{-1}$ below UCCSD(T) for the cc-pVDZ basis set].

The overestimation of barrier heights by UMP2 is not surprising given that it will have difficulty describing the transition state, which features stretched bonds and a larger degree of nondynamical electron correlation (electronic near-degeneracies) than the reactants. The underestimation of barrier heights by DFT is a well-known phenomenon related to the errors in the self-interaction energy. ${ }^{79-81}$ Self-interaction errors become large for structures away from equilibrium like transition states. An increase in the exact Hartree-Fock exchange from $0 \%$ in pure DFT to $20 \%$ in B3LYP to $50 \%$ in BHLYP leads to better error cancellation between the reactants and transition states for the computation of barrier heights. ${ }^{80,82,83}$

Using restricted orbitals causes most of the DFT barrier heights $\Delta E^{\ddagger}$ to increase. This significantly improves results for the reaction of $\mathrm{H}_{2}$ with $\mathrm{H}$, but for the other two symmetric reactions the RBHLYP barriers are overestimated compared to $\operatorname{RCCSD}(\mathrm{T})$. As we found above for transition state geometries, the $\operatorname{CCSD}(\mathrm{T})$ results are not very sensitive to the choice of UHF or ROHF reference, but the UMP2 and RMP2 barriers differ by as much as $10 \mathrm{kcal} \mathrm{mol}^{-1}$ for the reaction of HCC. with HCCH, the RMP2 results being closer to those from CCSD(T). We find that UMP2 suffers greatly from spin contamination for this reaction, as discussed in more detail below.

Zero-point vibrational energy corrections and thermal corrections are typically similar for different levels of theory for the symmetric reactions, although there are some significant differences for the reaction of $\mathrm{HCC}$. with $\mathrm{HCCH}$. In that case, UMP2 predicts anomalously small $\triangle \mathrm{ZPVE}$ and thermal corrections; the other methods are in general agreement with each other, but $\triangle \mathrm{ZPVE}$ can range from $2.2 \mathrm{kcal} \mathrm{mol}^{-1}$ (RB3LYP/cc-pVTZ) to $3.1 \mathrm{kcal} \mathrm{mol}^{-1}$ (UBHLYP/cc-pVTZ). As mentioned in the next section, the ethynyl radical has a challenging electronic structure, making the accurate prediction of geometries and vibrational frequencies more difficult than normal.

We may compare the theoretical results to experimentally-deduced activation energies, $E_{a}$, obtained by fitting reaction rates to an assumed Arrhenius form, although it must be kept in mind that these experimental values are subject to some uncertainty (see Section 2). These difficulties notwithstanding, we observe that the UCCSD(T)/cc-pVQZ value for $E_{a}(298)$ is within $0.4 \mathrm{kcal} \mathrm{mol}^{-1}$ of experiment for the $\mathrm{H}_{2}+\mathrm{H} \cdot$ reaction, which represents excellent agreement for a barrier height. Indeed, this agreement may be partially fortuitous, because the Wigner tunneling correction reduces the effective computed barrier and increases the error at this level of theory by $0.8 \mathrm{kcal} \mathrm{mol}^{-1}$. Because UCCSD $(\mathrm{T}) / \mathrm{cc}-\mathrm{pVQZ}$ computations will closely approach the Born-Oppenheimer limit for a three electron system, we ascribe the majority of this error to the approximate nature of the Wigner tunneling correction and to the inherent difficulties in comparing quantum barrier heights to phenomenologically deduced experimental $E_{a}$ values, as discussed previously. We conclude that more accurate comparisons between theory and experiment would appear to require going beyond simple transition state theory to more sophisticated dynamical treatments (including tunneling corrections), which could be used to compute reaction rates which 
may be compared directly with experiment.

For the reaction of methane with methyl radical, there is a larger disagreement of about 3.6 kcal $\mathrm{mol}^{-1}$ between experiment and $\operatorname{UCCSD}(\mathrm{T}) / \mathrm{cc}-\mathrm{pVTZ}$ for $E_{a}$. In this case, the theoretical results are in general agreement with each other, and they also agree with previous theoretical estimates in the literature. ${ }^{17,31,84,85}$ For example, robust composite methods like W1, G3X and CBS-QB3 predict $\Delta H^{\ddagger}(0)$ to be $17.5,18.4$ and $17.3 \mathrm{kcal} \mathrm{mol}^{-1}$, respectively, ${ }^{84}$ compared to our $\mathrm{UCCSD}(\mathrm{T}) / \mathrm{cc}-\mathrm{pVTZ}$ result for of $17.4 \mathrm{kcal} \mathrm{mol}^{-1}$. The Wigner tunneling correction reduces the discrepancy between experiment and our $\operatorname{UCCSD}(\mathrm{T}) / \mathrm{cc}-\mathrm{pVTZ}$ result for $E_{a}$ to $2.7 \mathrm{kcal} \mathrm{mol}^{-1}$ (or $2.9 \mathrm{kcal} \mathrm{mol}^{-1}$ when restricted orbitals are used). Given that improvements in the basis set tend to decrease the $\operatorname{CCSD}(\mathrm{T})$ activation energies, this disagreement would likely be reduced by an additional few tenths of a kcal mol ${ }^{-1}$ by larger basis set computations. The remaining disagreement is likely due to the unavoidable difficulties in comparing experimental and theoretical $E_{a}$ values, non-Arrhenius behavior of the reaction, errors in the Wigner tunneling correction, and/or possibly some uncertainty in the experimental value.

\subsection{Non-symmetric Reactions}

All the non-symmetric reactions we have studied involve ethynyl radical abstracting a hydrogen from representative hydrocarbon systems, namely $\mathrm{H}_{2}, \mathrm{CH}_{4}, \mathrm{C}_{2} \mathrm{H}_{4}, \mathrm{HC}\left(\mathrm{CH}_{3}\right)_{3}$ and $\mathrm{C}_{6} \mathrm{H}_{6}$. As the electronic structure of the ethynyl radical is a challenging subject of its own, we will begin our discussion of non-symmetric abstraction reactions with an overview of literature on the ethynyl radical.

\subsubsection{Ethynyl Radical (.CCH)}

The ethynyl radical has been the subject of numerous theoretical and experimental studies mainly because of its abundance in interstellar space ${ }^{86,87}$ and importance in combustion chemistry. ${ }^{88}$ The non-trivial electronic spectrum ${ }^{89-91}$ and hyperfine structure ${ }^{92}$ have been explored extensively. One of the notable features of the ethynyl radical is that the $\mathrm{A}^{2} \Pi$ excited electronic state lies only $3692 \mathrm{~cm}^{-1}(0.458 \mathrm{eV})$ above the ground $\mathrm{X}^{2} \Sigma^{+}$state. $^{93,94}$ This state arises from the promotion of one of the electrons in the filled $\pi$ orbitals to the half-filled carbon sigma radical orbital, $\cdots 1 \pi^{4} 5 \sigma^{1} \rightarrow \cdots 1 \pi^{3} 5 \sigma^{2}$. Previous theoretical studies have examined potential energy surfaces of some of the low-lying electronic states of $\mathrm{CCH},{ }^{91,95-97}$ including the conical intersection between the $\mathrm{X}^{2} \Sigma^{+}$and $\mathrm{A}^{2} \Pi$ states which occurs for stretched $\mathrm{C}-\mathrm{H}$ bond lengths. ${ }^{98}$ Figure 2 shows the bending potentials of some of the low-lying doublet states of $\mathrm{CCH}$ computed using equation-ofmotion (EOM) $\mathrm{CCSD}^{65}$ in conjunction with the large cc-pVQZ basis set. Note that the $\mathrm{A}^{2} \Pi$ state exhibits Renner-Teller splitting along the bending coordinate into ${ }^{2} A^{\prime}$ and ${ }^{2} A^{\prime \prime}$ components. ${ }^{91,96}$ However, the minimum-energy configuration of the $\mathrm{A}^{2} \Pi$ state, like that of the $\mathrm{X}^{2} \Sigma^{+}$state, is linear.

The close proximity of the $\mathrm{X}^{2} \Sigma^{+}$and $\mathrm{A}^{2} \Pi$ states in the ethynyl radical presents challenges for experimentalists and theoreticians alike. From an experimental standpoint, complex vibronic couplings have hampered efforts to find a unique absorption peak to monitor the presence and concentration of the radical in, for example, kinetics experiments. ${ }^{67}$ In theoretical studies, the strong 
vibronic coupling and conical intersection between the $\mathrm{X}^{2} \Sigma^{+}$and $\mathrm{A}{ }^{2} \Pi$ states can complicate the computation of spectra or reaction dynamics. In addition, although Hartree-Fock and postHartree-Fock methods correctly predict $\mathrm{CCH}$ to be linear, "pure" gradient-corrected functionals like BP86, BLYP and PWP86 predict a bent structure with a C-C-H angle of about $\sim 160^{\circ} .{ }^{99}$ Hybrid functionals with minor fractions of Hartree-Fock exchange also yield a bent structure when small basis sets are used. We therefore choose BHLYP as a more reliable functional in this case. A highly accurate and conclusive $a b$ initio study of the isolated ethynyl radical has been performed by Szalay et al. ${ }^{100}$ using a variety of multi-reference and other highly-correlated methods in conjunction with very large basis sets. Our best $\operatorname{CCSD}(\mathrm{T})$ bond lengths for $\cdot \mathrm{CCH}$ are within a few thousandths of an angstrom of the benchmark results of Szalay et al.

\subsubsection{Activation Energies}

Due to the high hydrogen affinity of the ethynyl radical, one would expect that the barriers for abstracting hydrogen from most hydrocarbons would be rather low, and that the abstraction process would proceed very quickly. Indeed, that is exactly what our calculations yield; our best estimates of the activation energies are $\leq 4 \mathrm{kcal} \mathrm{mol}^{-1}$ for the five representative non-symmetric reactions we studied. Theoretical results using unrestricted and restricted references are presented in Tables 4 and 5, respectively. UB3LYP and UBHLYP continue the pattern of underestimating barriers, and in most non-symmetric reactions where the barriers are already very small, they predict a barrierless path to the products. The tables contain dashes in those cases where we were unable to find a transition state corresponding to a collinear hydrogen abstraction reaction.

The larger cc-pVTZ basis set generally lowers classical barriers $\Delta E^{\ddagger}$ by about $1 \mathrm{kcal} \mathrm{mol}^{-1}$ compared to cc-pVDZ for RMP2 and UMP2 for the reaction of ethynyl with $\mathrm{H}_{2}$ or $\mathrm{CH}_{4}$, but it has a smaller effect (a few tenths of $1 \mathrm{kcal} \mathrm{mol}^{-1}$ ) for the DFT results. A more substantial basis set effect of $2.5 \mathrm{kcal} \mathrm{mol}^{-1}$ for $\Delta E^{\ddagger}$ is observed for UMP2 in the reaction of ethynyl radical with ethylene. MP2 generally provides $\Delta E^{\ddagger}$ values within a few tenths of one $\mathrm{kcal} \mathrm{mol}^{-1}$ of the more reliable $\operatorname{CCSD}(\mathrm{T})$ values, although larger discrepancies exist, particularly a difference of 2.9 kcal $\mathrm{mol}^{-1}$ for the reaction of ethynyl radical with ethylene when using unrestricted orbitals. Where DFT succeeds in finding a reaction barrier, the activation energies are underestimated compared to $\operatorname{CCSD}(\mathrm{T})$ but are generally in better agreement than for the symmetric reactions where the barriers are larger.

In a few instances for these non-symmetric reactions with very low barriers, ZPVE or temperature corrections to the classical barriers $\Delta E^{\ddagger}$ yield enthalpy changes $\Delta H^{\ddagger}$ which actually become negative. This occurs because we have located the transition states using the classical (BornOppenheimer) potential surface, with subsequent determination of enthalpy corrections. More sophisticated approaches may seek to find transition states on enthalpy or free-energy surfaces determined at the appropriate temperature. ${ }^{101}$ For present purposes, such results simply confirm that the reaction barriers are very low, if they exist at all.

In the case of $\cdot \mathrm{CCH}+\mathrm{HC}\left(\mathrm{CH}_{3}\right)_{3}$, we find the somewhat surprising result that even the classical barrier $\Delta E^{\ddagger}$ is negative (-0.4 at the UMP2/cc-pVDZ level of theory). When the reactants approach each other, they form a weakly bound van der Waals complex that is lower in energy than the separated reactants. As the reactants get even closer, they go over a barrier which has 
a higher energy than that of the van der Waals complex but a lower energy than that of the separated reactants; hence, the difference in energies between separated reactants and the transition state yields a "negative" barrier. This situation is illustrated schematically in Figure 3. At the UMP2/cc-pVDZ level of theory, a van der Waals complex with a well depth of $0.6 \mathrm{kcal} \mathrm{mol}^{-1}$ is formed when the ethynyl radical is $2.66 \AA$ away from the active hydrogen, while the transition state $\left(0.2 \mathrm{kcal} \mathrm{mol}^{-1}\right.$ above the van der Waals minimum but $0.4 \mathrm{kcal} \mathrm{mol}^{-1}$ below the separated reactants) is observed at $2.09 \AA$. Our theoretical findings are in agreement with the experimentally measured negative temperature dependence of the rate of this reaction and the associated experimentally deduced negative barrier $\left(-0.1 \mathrm{kcal} \mathrm{mol}^{-1}\right) \cdot{ }^{72}$ Based on similar observations for the reaction $\mathrm{CN}+\mathrm{C}_{2} \mathrm{H}_{6}$, Sims et al. ${ }^{102}$ suggest a mechanism involving the formation of a bound transient van der Waals complex. It is possible that similar van der Waals complexes may form in some of the other reactions we have studied, but that they are difficult to locate due to the very flat nature of the surface. Preliminary searches failed to locate a similar van der Waals complex in the reaction of ethynyl radical with methane, even when augmenting the basis set with diffuse functions (MP2/aug-cc-pVDZ). We do not rule out the possibility that these complexes may exist in some of the other reactions studied, but as they are not a focus of our study, we did not pursue them further.

For the reaction of ethynyl radical with $\mathrm{H}_{2}$, activation energies $E_{a}(298)-\mathrm{W}$ predicted at the CCSD(T)/cc-pVTZ level (3.5 and $3.8 \mathrm{kcal} \mathrm{mol}^{-1}$ with unrestricted and restricted orbitals, respectively) are higher than the experimentally derived barrier ${ }^{70}$ of $1.98 \pm 0.11 \mathrm{kcal} \mathrm{mol}^{-1}$ for the temperature range of 178 - $359 \mathrm{~K}$. Our UCCSD(T)/cc-pVTZ predicted $\Delta H^{\ddagger}(0)$ value of 3.0 $\mathrm{kcal} \mathrm{mol}^{-1}$ compares well to other high level theoretical works reported in the literature. In particular, UCCSD(T)/aug-cc-pVTZ//UCCSD(T)/6-311++G(2df,2p), G2//UQCISD6-311+G(d,p), QCISD/cc-pVTZ predict $\Delta H^{\ddagger}(0)$ for this reaction to be $3.1,{ }^{36} 2.5,{ }^{103}$ and $2.9,{ }^{104}$ respectively.

For the reaction of ethynyl radical with $\mathrm{CH}_{4}$, the tunneling corrected activation barrier, $E_{a}(298)-\mathrm{W}$, computed at RCCSD(T)/cc-pVTZ level [with vibrational frequencies evaluated at the RCCSD(T)/cc-pVDZ level] only differs by $0.6 \mathrm{kcal} \mathrm{mol}^{-1}$ from experiment. The corresponding value for $\Delta H^{\ddagger}(0), 1.7 \mathrm{kcal} \mathrm{mol}^{-1}$, is somewhat smaller than the comparable literature value ${ }^{35,105}$ of $2.6 \mathrm{kcal} \mathrm{mol}^{-1}$ at the CCSD(T)/aug-cc-pVTZ//CCSD(T)/6-31G(d,p)+ZPVE[UMP2/6-311++G(3df,2p)] level of theory, and noticeably smaller than MPW1K/6-311++G(3df,2p)//MPW1K/6-311++G(d,p) value of $4.7 \mathrm{kcal} \mathrm{mol}^{-1}$.

Hydrogen abstraction from isobutane by the ethynyl radical is of particular importance since isobutane has been used as a cluster model to represent diamond C(111) surface. ${ }^{38,106,107}$ The absence of a hydrogen abstraction barrier for this reaction would thus indicate that ethynyl radical or any tool with an ethynyl radical tip should serve as a convenient abstraction tool. ${ }^{17}$

Finally, the reaction of ethynyl radical with benzene can serve as a good model for hydrogen abstraction from delocalized $\pi$ systems. For both restricted and unrestricted orbitals, MP2/cc-pVDZ and $\operatorname{CCSD}(\mathrm{T}) / \mathrm{cc}-\mathrm{pVDZ}$ yield $\mathrm{E}_{a}(298)-\mathrm{W}$ values in the range of 1.5 to $2.3 \mathrm{kcal} \mathrm{mol}^{-1}$. However, using the larger cc-pVTZ basis for MP2 lowers $\mathrm{E}_{a}(298)-\mathrm{W}$ to $0.8 \mathrm{kcal} \mathrm{mol}^{-1}$ for unrestricted orbitals, and it actually becomes negative $\left(-0.5 \mathrm{kcal} \mathrm{mol}^{-1}\right)$ for restricted orbitals (the "negative" barrier here is, again, simply a consequence of locating the transition state on the Born-Oppenheimer surface, and the approximate nature of the Wigner tunneling correction). These rather small 
barriers are in general agreement with experimental work ${ }^{108}$ suggesting that this reaction has no barrier.

\subsubsection{Enthalpies of Reaction}

So far, we have focused on activation energies, where direct comparison between theory and experiment is difficult. Let us now turn to enthalpies of reaction $\Delta H$, where comparison with experiment is more straightforward. Here we will compare theoretical values of the reaction enthalpies at 298 $\mathrm{K}, \Delta H(298)$, against the corresponding experimental values obtained from addition and subtraction of standard heats of formation, $\Delta H_{f}^{o}(298)$. For the symmetric reactions, of course the reaction enthalpies are zero by definition. For the non-symmetric reactions, results are presented in Tables 4 and 5.

As shown in the tables, B3LYP, BHLYP and CCSD $(\mathrm{T})$ predict enthalpies of reaction that agree reasonably well with experiment. For most reactions, $\Delta H(298)$ calculated using $\operatorname{CCSD}(\mathrm{T})$ matches experiment within about $2 \mathrm{kcal} \mathrm{mol}^{-1}$. Larger differences are seen for the reaction of ethynyl radical with benzene, or for the reaction of ethynyl radical with isobutane (when using restricted orbitals). Our results confirm a previous observation ${ }^{83}$ that the BHLYP functional, while improving on abstraction barriers predicted by B3LYP, leads to somewhat larger errors for the reaction enthalpies. In general, B3LYP enthalpies of reaction are in better agreement with experiment while the BHLYP predictions deviate from their B3LYP counterparts by up to 2.7 kcal mol ${ }^{-1}$.

It is surprising to note that UMP2 gives estimates of $\Delta H(298)$ that are $8-20 \mathrm{kcal} \mathrm{mol}^{-1}$ lower than the corresponding experimental values (see Table 4); additionally, this anomaly does not disappear when the larger cc-pVTZ basis is used. However, when we employ a restricted reference via RMP2, as shown in Table 5, this significantly improves the $\Delta H(298)$ results compared to the UMP2 values. This observation highlights the problems of spin contamination when UHF references are used and underscores the need to carefully consider the choice of reference wavefunction in computations involving these radical-molecule reactions. In the next section, we examine the extent of spin contamination in the UHF-based results. We attribute most of the difference between UMP2 and experimental $\Delta H(298)$ values to the uneven effect of spin contamination between reactants and products. Apart from the MP2 method, the choice of restricted or unrestricted orbitals makes little difference in most of the theoretical reaction enthalpies, with most changes being 2 kcal mol ${ }^{-1}$ or less. Figures 4 and 5 display the differences between results obtained using restricted and unrestricted references for computations of barrier heights and reaction energies, respectively.

\subsection{Spin Contamination}

One potential problem with computations based upon unrestricted orbitals is that they can feature significant contamination by higher-multiplicity spin states. Although highly-correlated methods such as UCCSD $(\mathrm{T})$ have been shown to be rather insensitive to spin contamination, ${ }^{109,110}$ significant problems can arise for lower-order methods, including UMP2. ${ }^{111-114}$ Table 6 examines the degree of spin contamination for several species considered here using the UMP2 and UCCSD(T) methods. Spin contamination is considered to be a minimal problem in density-functional the- 
ory $^{115}$ and it is not well-defined; ${ }^{113}$ nevertheless, Table 6 also includes UB3LYP and UBHLYP results for comparison. These DFT methods are not significantly affected by spin contamination, as indicated by expectation values of $\left\langle\hat{S}^{2}\right\rangle$ which are very close to the ideal 0.75 for a doublet radical. Although the spin contamination in the UMP2 wavefunction for some radicals like $\cdot \mathrm{C}\left(\mathrm{CH}_{3}\right)_{3}$ and $\cdot \mathrm{CH}_{3}$ is fairly small, it is significant for the $\cdot \mathrm{CCH}, \mathrm{C}_{2} \mathrm{H}_{3}$, and $\cdot \mathrm{C}_{6} \mathrm{H}_{5}$ radicals. Spin contamination in the ethynyl radical in particular is a well-known problem and it has been used to explain the inaccurate isotropic hyperfine couplings predicted by most ab initio methods using spin-unrestricted formalisms. ${ }^{99}$ Note that significant spin contamination is also observed for the transition states considered. Because the degree of spin contamination is similar $\left(<\hat{S}^{2}>\sim 1.05\right)$ for $\cdot \mathrm{CCH}$ and the transition states for reactions of $\cdot \mathrm{CCH}$, the spin contamination errors largely cancel when computing activation barriers. However, in several of the reactions considered, there is less spin contamination in the products, leading to an erroneous lowering of the UMP2 enthalpies of reaction. In the case of the reaction $\mathrm{HCC} \cdot+\mathrm{C}_{6} \mathrm{H}_{6} \rightarrow \mathrm{HCCH}+\cdot \mathrm{C}_{6} \mathrm{H}_{5}$, the highly spin contaminated phenyl radical product $\left.\left(<\hat{S}^{2}\right\rangle=1.21\right)$ leads to a significant raising of the UMP2 value for $\Delta H(298)$.

Although using an ROHF reference conveniently alleviates spin contamination by quartets and larger multiplets from our doublet systems, it has been known to occasionally give artifactual results that have no physical basis, ${ }^{77,78}$ and even in the present study, RMP2 predicts non-symmetric transition states for our three symmetric reactions (see Figure 1 and the previous discussion of transition state geometries). Fortunately, this unphysical result disappears for the more robust $\operatorname{RCCSD}(\mathrm{T})$ method.

\subsection{Electron Correlation Effects Beyond CCSD(T)}

One would expect the reactants and products in the present study to be dominated by a single electron configuration, so that the single-reference methods employed here should give fairly reliable results. Indeed, our computations did not show signs of any severe electronic near-degeneracies in any of the reactant or product species. However, the transition states involve bonds which are in the process of being formed and broken, and additional electron configurations may contribute significantly to the zeroth-order wavefunction. In this case, the reliability of single-reference methods might be degraded, and it might be necessary to employ multi-reference methods to achieve high-accuracy results. ${ }^{60}$

In order to test for the possible importance of electron correlation effects beyond those described by $\operatorname{CCSD}(\mathrm{T})$, where feasible we have performed full configuration interaction (FCI) computations which exactly solve the electronic Schrödinger equation within the given one-particle basis set. Table 7 shows that, for the systems where we could afford the very expensive FCI computations, the $\operatorname{CCSD}(\mathrm{T})$ and FCI barriers are very similar (within $0.15 \mathrm{kcal} \mathrm{mol}^{-1}$ ), indicating that $\operatorname{CCSD}(T)$ is sufficient to describe electron correlation effects in these systems. The difference between $\operatorname{CCSD}(\mathrm{T})$ and $\mathrm{FCI}$ for the reaction energies $\Delta E$ of the two non-symmetric reactions is $0.20-0.25 \mathrm{kcal} \mathrm{mol}^{-1}$, somewhat larger than the differences observed for barrier heights. This correction remains, however, a very small fraction of the overall reaction energy. Analysis of the FCI wavefunctions for the species in Table 7 demonstrates that none of the leading coefficients, $C_{0}$, is below 0.91 , and none of the second largest coefficients, $C_{1}$ is greater than 0.14 . Additionally, T1 
diagnostic $^{116,117}$ for our RCCSD(T)/cc-pVDZ computations of transition states was never above the value of 0.02 ; Lee and co-workers argue that multi-reference systems typically feature values above this. Thus the similarity of $\mathrm{CCSD}(\mathrm{T})$ to FCI, the leading FCI coefficients, and the T1 diagnostics agree that these simple hydrogen abstraction reactions do not appear to have a large multi-reference character.

\subsection{Abstraction Tool}

For mechanosynthesis of diamond to be realized, it is imperative that the abstraction and deposition tools have favorable thermodynamics, facile kinetics, and good positional control. ${ }^{6-11}$ The most natural tool for these purposes would be something like a scanning probe microscopy (SPM) tip, ${ }^{7}$ which has already been used for sub-nanometer manipulation of atoms. ${ }^{15}$ Given its low barriers and high exothermicities for the hydrogen abstraction reactions discussed above, the ethynyl radical might be an excellent choice for attaching to an SPM tip to form a hydrogen abstraction tool. ${ }^{6,17-19}$ Assuming that the ethynyl moiety might be attached via a hydrocarbon connector, as a somewhat larger model system we have considered an ethynyl radical attached to a t-butyl group as shown in Figure 6.

One interesting question to ask of this model is whether it exhibits any energetically accessible but undesirable alternative reactions which might hamper its function as a tool for abstracting hydrogens from a hydrocarbon surface. In particular, we considered the possibility that the tooltip might react with itself, with the radical tip forming bonds with carbon or hydrogen atoms of the t-butyl base. In a limited search for such reactions, we found only one relevant transition state, that of a hydrogen auto-abstraction, depicted in Figure 7. This transition state is $57 \mathrm{kcal} \mathrm{mol}^{-1} \mathrm{up}$ in energy at the UMP2/cc-pVDZ level of theory and hence is not expected to be easily accessible at modest temperatures.

Another important consideration in evaluating possible abstraction tools is their structural rigidity. If a candidate tool is too flexible, it may exhibit large-amplitude oscillations which could impair the positional selectivity of the abstraction process. In particular, if the bending frequencies of the radical tip are too low, then modest temperatures will be sufficient to populate highly excited vibrational levels of these bending modes. The isolated ethynyl radical, $\cdot \mathrm{CCH}$, features an experimentally-determined ${ }^{118}$ bending frequency of $372 \mathrm{~cm}^{-1}$, which might be considered an intermediate value between high-energy and low-energy bending modes. We note that the theoretical computation of vibrational frequencies using UMP2, UB3LYP, UBHLYP or UCCSD(T) are typically accurate to a few percent, but the errors for radicals can be somewhat higher. ${ }^{119}$ We see unusually large discrepancies between different theoretical methods or between theory and experiment for ethynyl-type radicals, and the UCCSD(T)/cc-pVDZ prediction for the degenerate bending frequency of $\mathrm{CCH}$ is $310 \mathrm{~cm}^{-1}$, somewhat farther from experiment than one might expect for this high level of theory. Nevertheless, ab initio computations should provide at least reasonable estimates of these bending frequencies in related systems. We determined the bending frequency of the propynyl radical $\left(\mathrm{CH}_{3} \mathrm{CC} \cdot\right)$ to be $169 \mathrm{~cm}^{-1}$ at the UCCSD(T)/cc-pVDZ level of theory, a somewhat lower frequency than that of $\cdot \mathrm{CCH}$. For our model tooltip in Figure 6, with an ethynyl group attached to a t-butyl base, the UMP2/cc-pVDZ level of theory predicts a value of $202 \mathrm{~cm}^{-1}$, again an intermediate value, for the bending mode of the ethynyl group. These re- 
sults suggest that precise positional control might become difficult at elevated temperatures unless modifications are made to introduce more rigidity into the system. At low temperatures, however, a bending frequency of around $\sim 200 \mathrm{~cm}^{-1}$ should be sufficient to prevent large uncertainties in the position of the radical tip. The $\mathrm{C}-\mathrm{C}-\mathrm{C}$ bending potential for the model tooltip (using the simple C-C-C internal coordinate, which is very similar to the corresponding normal mode) is shown in Figure 8. The fractional Boltzmann populations, $f_{n}$, for the evenly spaced energy levels $n$ of a harmonic oscillator of frequency $\nu$ (in $\mathrm{Hz}$ ) at temperature $T$ are given by

$$
f_{n}=\left(1-e^{-h \nu / k_{b} T}\right) e^{-n h \nu / k_{b} T} .
$$

Using the value of $202 \mathrm{~cm}^{-1}$ and ignoring any coupling of the $\mathrm{C}-\mathrm{C}-\mathrm{C}$ bending mode with other modes, the Boltzmann populations of its $n=0, n=1, n=2$ and $n=3$ levels are $62 \%, 24 \%, 9 \%$ and $3 \%$, respectively, at $298 \mathrm{~K}$. Estimating the classical turning points from the bending potential in Figure 8, the positional uncertainties at the end of the tooltip for these vibrational levels are around $0.12,0.15,0.19$, and $0.24 \AA$, respectively. Considering the distance of $2.5 \AA$ between two adjacent hydrogens on diamond $\mathrm{C}(111)$ surface terminated with hydrogens, ${ }^{17}$ the positional uncertainty even for a vibrationally excited tooltip is miniscule. On the basis of this analysis, the tool should have good positional selectivity at modest temperatures.

Finally, it is conceivable that the presence of unusually low-lying excited electronic states might affect the operation of radical tooltips if those excited states have unfavorable features in contrast to those noted for the ground state. As mentioned previously, the A ${ }^{2} \Pi$ state lies only $0.458 \mathrm{eV}$ above the ground state according to experiment. ${ }^{94}$ Our computations suggest that this excited state is unreactive in collinear hydrogen abstraction reactions because it fills the sigma orbital which was singly occupied and reactive in the ground state. Although $0.458 \mathrm{eV}$ is a small gap on the scale of electronic excitation energies, nevertheless, we do not expect it to significantly impair the operation of ethynyl-based tooltips at modest temperatures. First of all, this first excited state remains linear, like the ground state (see Figure 2), so that if this state were accessed, it should not by itself contribute to any positional uncertainty in the tooltip. Secondly, rovibrational energy levels within the $\mathrm{A}^{2} \Pi$ electronic state are significantly perturbed by levels of the $\mathrm{X}^{2} \Sigma^{+}$ electronic state, ${ }^{93,120}$ meaning that nominally unreactive levels of the A state may borrow some reactive character due to their mixing with the $\mathrm{X}$ state. Thirdly, and most importantly, using the experimental energy gap of $0.458 \mathrm{eV}$ yields a very small Boltzmann population for the A state only $\sim 10^{-8}$ at $298 \mathrm{~K}$. At liquid nitrogen temperature of $77 \mathrm{~K}$, that ratio becomes truly negligible at $\sim 10^{-30}$. If, in spite of these small probabilities, the $\mathrm{A}^{2} \Pi$ electronic state were to be accessed, it may not be long-lived. Unfortunately it is not possible based on current data to estimate the lifetime of all the potentially relevant vibronic levels of nominal $\mathrm{A}^{2} \Pi$ character, but we note that a study by Wittig and co-workers ${ }^{121}$ indicates spontaneous emission lifetimes of at least some of these levels to be on the order of 20-60 $\mu$ s (the same order of magnitude one would expect by scaling spontaneous emission lifetimes of isoelectronic species ${ }^{122,123}$ by the cube of the ratio of the energy gaps between the ground and excited states). ${ }^{124,125}$

Of course the electronic structure of actual tooltips will differ somewhat from that of the simple ethynyl radical, and it is important to ask if the gap between the ground and first excited states might decrease for larger molecular systems. In partial exploration of this question, we computed 
the UCCSD $(\mathrm{T})$ vertical and adiabatic excitation energies for the low-lying excited states of the ethynyl and propynyl radicals and for our model tooltip. Table 8 shows that both the vertical and adiabatic excitation energies for the $\mathrm{X} \rightarrow \mathrm{A}$ transitions are low for these species. For our proposed abstraction tool (Figure 6), using the UCCSD(T)/cc-pVDZ adiabatic excitation energy of $0.20 \mathrm{eV}$, we estimate the ratio of the Boltzmann population of the excited state to the ground state to be $\sim 10^{-4}$ at $298 \mathrm{~K}$ and $\sim 10^{-14}$ at $77 \mathrm{~K}$. We therefore expect that the tooltip radical should remain in its ground electronic state at modest temperatures of operation. Regarding the contribution to reaction error rate caused by tooltip unreactivity in the excited state and the required transition time from excited to ground state, if a $\sim 10^{-4}$ error rate at $298 \mathrm{~K}$ or a $\sim 10^{-14}$ error rate at 77 $\mathrm{K}$ is acceptable then the speed of tool operation is unconstrained by the required transition time.

\section{Conclusions}

The abstraction of hydrogens from prototypical hydrocarbon molecules has been studied using high level $a b$ initio techniques. The calculated activation barriers and enthalpies of reaction are found to be in good agreement with experiment. In general, MP2 overestimates barriers and is particularly sensitive to spin contamination of the reference wavefunction. Density functional methods, namely B3LYP and BHLYP, significantly underestimate barriers due to self-interaction errors. The more reliable $\operatorname{CCSD}(\mathrm{T})$ method predicts barrier heights and enthalpies of reaction which are generally in excellent agreement with experiment. The hydrogen abstraction activation energy from $s p^{2}$ and $s p^{3}$ carbons by ethynyl radical is less than $3 \mathrm{kcal} \mathrm{mol}^{-1}$. For the reaction of ethynyl radical with isobutane, the abstraction reaction is barrierless. This makes ethynyl-type radicals appealing as possible tooltips for use in the mechanosynthesis of diamond, particularly at low temperatures where they would have a high degree of positional selectivity and control.

\section{Acknowledgments}

We thank Profs. Curt Wittig (USC), Robert Field (MIT), and David Yarkony (Johns Hopkins) for helpful discussions regarding excited states of $\mathrm{CCH}$. We also thank Prof. Paul Wine (Georgia Tech) for helpful discussions. C.D.S. acknowledges a National Science Foundation CAREER Award (grant no. CHE-0094088). The Center for Computational Molecular Science and Technology is funded through an NSF CRIF grant from NSF (CHE-0443564) by Georgia Tech. R.A.F. acknowledges research grants from Institute for Molecular Manufacturing (IMM), Alcor Foundation, Kurzweil Foundation and LEF. 


\section{References}

[1] M. J. Knapp and J. Klinman, Eur. J. Biochem. 269, 3113 (2002).

[2] B. Balasubramanian, W. K. Pogozelskidagger, and T. D. Tullius, Proc. Natl. Acad. Sci. 95, 9738 (1998).

[3] M. D. Le Page and B. R. James, Chem. Comm., 1647 (2000).

[4] P. W. May, Endeavour 19, 101 (1995).

[5] H. T. Hall, J. Chem. Ed. 38, 484 (1961).

[6] K. E. Drexler, J. Vac. Sci. Technol. B 9, 1394 (1991).

[7] H. H. Farrell and M. Levinson, Phys. Rev. B 31, 3593 (1985).

[8] K. E. Drexler, Nanosystems: Molecular Machinery, Manufacturing, and Computation. John Wiley \& Sons, New York, 1992.

[9] R. C. Merkle, Chem. Design Automation News 9, 1 (1993).

[10] R. C. Merkle, Nanotechnology 8, 149 (1997).

[11] R. C. Merkle and R. A. Freitas Jr., J. Nanosci. Nanotech. 3, 319 (2003).

[12] J. Peng, R. A. Freitas Jr., and R. C. Merkle, J. Comput. Theor. Nanosci. 1, 62 (2004).

[13] J. Peng, R. A. Freitas Jr., R. C. Merkle, J. R. Von Ehr, and G. D. Skidmore, J. Comput. Theor. Nanosci. 3, 28 (2006).

[14] D. J. Mann, J. Peng, R. A. Freitas Jr., and R. C. Merkle, J. Comput. Theor. Nanosci. 1, 71 (2004).

[15] X. Y. Chang, M. Perry, J. Peploski, D. L. Thompson and L. M. Raff, J. Chem. Phys. 99, 4748 (1993); J. W. Lyding, K. Hess, G. C. Abeln, D. S. Thompson, J. S. Moore, M. C. Hersam, E. T. Foley, J. Lee, Z. Chen, S. T. Hwang, H. Choi, P. H. Avouris and I. C. Kizilyalli, Appl. Surf. Sci. 130, 221 (1998); W. Ho and H. Lee, Science. 286, 1719(1999); L. J. Lauhon and W. Ho, J. Phys. Chem. 105, 3987 (2000); S. Hla and K. Rieder, Ann. Rev. Phys. Chem. 54, 307 (2003).

[16] E. T. Foley, A. F. Kam, J. W. Lyding and P.H. Avouris, Phys. Rev. Lett. 80, 1336 (1998); M. C. Hersam, G. C. Abeln and J. W. Lyding, Microelectronic Engineering. 47, 235 (1999); N. Oyabu, O. Custance I. Yi, Y. Sugawaran and S. Morita. Phys. Rev. Lett. 90, 176102 (2003).

[17] C. B. Musgrave, J. K. Perry, R. C. Merkle, and W. A. Goddard III, Nanotechnology 2, 187 (1991). 
[18] S. B. Sinnott, R. J. Colton, C. T. White, and D. W. Brenner, Surf. Sci. 316, L1055 (1994).

[19] D. W. Brenner, S. B. Sinnott, J. A. Harrison, and O. A. Shenderova, Nanotechnology 7, 161 (1996).

[20] J. A. Pople, M. Head-Gordon, D. J. Fox, K. Raghavachari, and L. A. Curtiss, J. Chem. Phys. 90, 5622 (1989).

[21] L. A. Curtiss, K. Raghavachari, G. W. Trucks, and J. A. Pople, J. Chem. Phys. 94, 7221 (1991).

[22] L. A. Curtiss, K. Raghavachari, and J. A. Pople, J. Chem. Phys. 98, 1293 (1993).

[23] L. A. Curtiss, K. Raghavachari, P. C. Redfern, V. Rassolov, and J. A. Pople, J. Chem. Phys. 109, 7764 (1998).

[24] L. A. Curtiss, P. C. Redfern, K. Raghavachari, V. Rassolov, and J. A. Pople, J. Chem. Phys. 110, 4703 (1999).

[25] A. G. Baboul, L. A. Curtiss, P. C. Redfern, and K. Raghavachari, J. Chem. Phys. 110, 7650 (1999).

[26] J. M. L. Martin and G. de Oliveira, J. Chem. Phys. 111, 1843 (1999).

[27] A. D. Boese, M. Oren, O. Atasoylu, J. M. L. M. J. Gauss, and M. Kállay, J. Chem. Phys. 111, 1843 (1999).

[28] A. Tajti, P. G. Szalay, A. Császár, M. Kállay, J. Gauss, E. F. Valeev, B. A. Flowers, J. Vazquez, and J. F. Stanton, J. Chem. Phys. 121, 11599 (2004).

[29] A. Dybala-Defratyka, P. Paneth, J. Pu, and D. G. Truhlar, J. Phys. Chem. A 108, 2475 (2004).

[30] Y. Chuang, E. L. Coitiño, and D. G. Truhlar, J. Phys. Chem. A 104, 446 (2000).

[31] J. A. Litwinowicz, D. W. Ewing, S. Jurisevic, and M. J. Manka, J. Phys. Chem 99, 9709 (1995).

[32] S. Skokov and R. A. Wheeler, Chem. Phys. Lett. 271, 251 (1997).

[33] J. Peeters, H. Van Look, and B. Ceursters, J. Phys. Chem. 100, 15124 (1996).

[34] H. Van Look and J. Peeters, J. Phys. Chem. 99, 16284 (1995).

[35] H. M. T. Nguyen, A. K. Chandra, S. A. Carl, and M. T. Nguyen, J. Mol. Struct (THEOCHEM) 732, 219 (2005).

[36] J. Peeters, B. Ceursters, H. M. T. Nguyen, and M. T. Nguyen, J. Chem. Phys. 116, 3700 (2002). 
[37] J. Peeters, B. Ceursters, H. M. T. Nguyen, and M. T. Nguyen, Chem. Phys. 262, 243 (2000).

[38] M. Page and D. W. Brenner, J. Amer. Chem. Soc. 113, 3270 (1991).

[39] S. P. Walch and R. C. Merkle, Nanotechnology 9, 285 (1998).

[40] F. N. Dzegilenko, D. Srivastava, and S. Saini, Nanotechnology 9, 325 (1998).

[41] T. H. Dunning Jr., J. Chem. Phys. 90, 1007 (1989).

[42] R. A. Kendall, T. H. Dunning Jr., and R. J. Harrison, J. Chem. Phys. 96, 6796 (1992).

[43] K. Raghavachari, G. W. Trucks, J. A. Pople, and M. Head-Gordon, Chem. Phys. Lett. 157, 479 (1989).

[44] P. J. Stephens, F. J. Devlin, C. F. Chabalowski, and M. J. Frisch, J. Phys. Chem. 98, 11623 (1994).

[45] A. D. Becke, J. Chem. Phys. 98, 1372 (1993).

[46] MOLPRO 2002.6 is a package of ab initio programs designed by Werner, H.-J. and Knowles, P. J., with contributions from Amos, R. D., Bernhardosson, A., Berning, A., Celani, P., Cooper, D. L., Deegan, M. J. O., Dobbyn, A. J., Eckert, F., Hampel, C., Hetzer, G., Knowles, P. J., Korona, T., Lindh, R., Lloyd, A. W., McNicholas, S. J., Manby, F. R., Meyer, W., Mura, M. E., Nicklass, A., Palmieri, P., Pitzer, R., Rauhut, G., Schutz, M., Schumann, U., Stoll, H., Stone, A. J., Tarroni, R., Thorsteinsson, T., and Werner, H.-J.

[47] R. J. Sreeruttun, P. Ramasami, G. Yan, C. S. Wannere, P. V. R. Schleyer, and H. F. Schaefer, Intl. J. of. Mass. Spec. 241, 295 (2005).

[48] J. Xiao, Z. Li, J. Liu, L. Sheng, and C. Sun, J. of. Comp. Chem. 23, 1456 (2002).

[49] A. D. Becke, Phys. Rev. A 38, 3098 (1988).

[50] C. Lee, W. Yang, and R. G. Parr, Phys. Rev. B 37, 785 (1988).

[51] B. J. Lynch, P. Fast, M. Harris, and D. J. Truhlar, J. Phys. Chem. A 104, 4811 (2000).

[52] M. L. Abrams and C. D. Sherrill, Chem. Phys. Lett. 404, 284 (2005).

[53] A. Dutta and C. D. Sherrill, J. Chem. Phys. 118, 1610 (2003).

[54] J. Olsen, P. Jørgensen, H. Koch, A. Balková, and R. J. Bartlett, J. Chem. Phys. 104, 8007 (1996).

[55] R. J. Bartlett and J. F. Stanton, Applications of post-hartree-fock methods: A tutorial, in Reviews in Computational Chemistry, edited by K. B. Lipkowitz and D. B. Boyd, volume 5, pages 65-169. VCH Publishers, New York, 1994. 
[56] J. F. Stanton, J. Gauss, W. J. Lauderdale, J. D. Watts, and R. J. Bartlett, ACES II, The package also contains modified versions of the MOLECULE Gaussian integral program of J. Almlöf and P. R. Taylor, the ABACUS integral derivative program written by $\mathrm{T}$. U. Helgaker, H. J. Aa. Jensen, P. Jørgensen and P. R. Taylor, and the PROPS property evaluation integral code of P. R. Taylor.

[57] R. D. Amos, J. S. Andrews, N. C. Handy, and P. J. Knowles, Chem. Phys. Lett. 185, 256 (1991).

[58] P. J. Knowles, C. Hampel, and H.-J. Werner, J. Chem. Phys. 99, 5219 (1993).

[59] J. D. Watts, J. Gauss, and R. J. Bartlett, J. Chem. Phys. 98, 8718 (1993).

[60] C. D. Sherrill, Bond breaking in quantum chemistry, in Annual Reports in Computational Chemistry, edited by D. Spellmeyer, volume 1, pages 45-54. Elsevier, Amsterdam, 2005.

[61] M. R. Hoffmann and K. G. Dyall, editors, Low-Lying Potential Energy Surfaces, volume 828 of ACS Symposium Series. American Chemical Society, Washington, D.C., 2002.

[62] K. Hirao, editor, Recent Advances in Multireference Methods, volume 4 of Recent Advances in Computational Chemistry. World Scientific, Singapore, 1999.

[63] C. D. Sherrill and H. F. Schaefer, The configuration interaction method: Advances in highly correlated approaches, in Advances in Quantum Chemistry, edited by P.-O. Löwdin, volume 34, pages 143-269. Academic Press, New York, 1999.

[64] T. D. Crawford, C. D. Sherrill, E. F. Valeev, J. T. Fermann, R. A. King, M. L. Leininger, S. T. Brown, C. L. Janssen, E. T. Seidl, J. P. Kenny, and W. D. Allen, PSi 3.2, 2003.

[65] J. F. Stanton and R. J. Bartlett, J. Chem. Phys. 98, 7029 (1993).

[66] D. R. Lide, ed., Handbook of Chemistry and Physics. CRC Press, Boca Raton, FL, 1996.

[67] A. H. Laufer and A. Fahr, Chem. Rev. 104, 2814 (2004).

[68] W. R. Shulz and D. J. Leroy, J. Chem. Phys. 42, 3869 (1965).

[69] J. M. Tedder, Agnew. Chem. Int. Ed. Engl. 21, 401 (1982).

[70] B. J. Opansky and S. R. Leone, J. Phys. Chem. 100, 19904 (1996).

[71] B. J. Opansky and S. R. Leone, J. Phys. Chem. 100, 4888 (1996).

[72] R. J. Hobbler, B. J. Opansky, and S. R. Leone, J. Phys. Chem. A. 101, 1338 (1997).

[73] J. I. Steinfeld, J. S. Francisco, and W. L. Hase, Chemical Kinetics and Dynamics. Prentice Hall, New Jersey, USA, 1989.

[74] E. Wigner, Z. Phys. Chem. B 19, 203 (1932). 
[75] R. P. Bell, The Tunnel Effect in Chemistry. Chapman and Hall, London, 1980.

[76] G. S. Hammond, J. Am. Chem. Soc. 77, 334 (1955).

[77] W. T. Borden, E. R. Davidson, and D. Feller, Tetrahedron 38, 737 (1982).

[78] E. R. Davidson and W. T. Bowden, J. Phys. Chem. 87, 4783 (1983).

[79] B. Johnson, C. Gonzalez, P. Gill, and J. Pople, Chem. Phys. Lett. 221, 100 (1994).

[80] S. Patchkovskii and T. Ziegler, J. Chem. Phys. 116, 7806 (2002).

[81] Y. Zhang and W. Yang, J. Chem. Phys. 109, 2604 (1999).

[82] B. J. Lynch, P. L. Fast, M. Harris, and D. G. Truhlar, J. Phys. Chem. A 104, 4811 (2000).

[83] B. J. Lynch and D. G. Truhlar, J. Phys. Chem. A 105, 2936 (2001).

[84] M. L. Coote, J. Phys. Chem. A 108, 3865 (2004).

[85] H. Basch and S. Hoz, J. Phys. Chem. A 101, 4416 (1997).

[86] K. D. Tucker, M. L. Kutner, and P. Thaddeus, Astrophys. J. 193, L115 (1974).

[87] C. Henkel, J. B. Whiteoak, L. A. Nyman, and J. Hajru, Astron. Astrophys. 230, L5 (1990).

[88] K. C. Smyth, P. J. H. Tjossem, A. Hamines, and J. H. Miller, Combust. Flame 79, 366 (1990).

[89] Y.-C. Hsu, J. J.-M. Lin, D. Papoušek, and J.-J. Tsai, J. Chem. Phys. 98, 6690 (1993).

[90] S. Shih, S. D. Peyerimhoff, and R. J. Buekner, J. Mol. Spect. 64, 167 (1977).

[91] Q. Cui and M. Morokuma, J. Chem. Phys. 108, 8 (1998).

[92] M. Perić, S. D. Peyerimhoff, and R. J. Buekner, Z. Phys. D. 24, 177 (1992).

[93] P. G. Carrick, A. J. Merer, and R. F. Curl, J. Chem. Phys. 78, 3652 (1983).

[94] Y. C. Hsu, Y. J. Shui, and C. M. Lin, J. Chem. Phys. 103, 5919 (1995).

[95] H. Thümmel, M. Perić, S. D. Peyerimhoff, and R. J. Buekner, Z. Phys. D. 13, 307 (1989).

[96] D. Duflot, J. Robbe, and J. P. Flament, J. Chem. Phys. 100, 1236 (1994).

[97] M. Boggio-Pasqua, P. Halvick, M. T. Rayez, J. C. Rayez, and J. M. Robbe, J. Phys. Chem. A 102, 2009 (1998).

[98] A. Mebel, M. Baer, and S. Lin, J. Chem. Phys. 112, 10703 (200).

[99] L. A. Eriksson and A. Laaksonen, J. Chem. Phys. 105, 8195 (1996). 
[100] P. A. Szalay, L. S. Thøgersen, M. Kállay, and J. Gauss, J. Phys. Chem. A. 108, 3030 (2004).

[101] A. D. Isaacson and D. G. Truhlar, J. Chem. Phys. 76, 1380 (1982).

[102] I. Sims, J. L. Queffelec, D. Travers, B. R. Rowe, L. B. Herbert, J. Karthäuser, and I. W. M. Smith, Chem. Phys. Lett. 211, 461 (1993).

[103] X. Zhang, Y. Ding, Z. Li, X. Huang, and C. Sun, J. Phys. Chem. A 104, 8375 (2000).

[104] Y. Kurosaki and T. Takayanagi, J. Chem. Phys. 113, 4060 (2000).

[105] B. Ceursters, H. M. T. Nguyen, J. Peeters, and M. T. Nguyen, Chem. Phys. Lett. 329, 412 (2000).

[106] K. A. Jackson, Proceedings of the Second International Conference. Materials Research Society, Pittsburgh,PA, 1991.

[107] A. Ricca, C. Bauschlicher Jr., J. Kang, and C. Musgrave, Surf. Sci. 429, 199 (1999).

[108] F. Goulay and S. R. Leone, J. Phys. Chem. A. 110, 1875 (2006).

[109] P. G. Szalay, J. Vázquez, C. Simmons, and J. F. Stanton, J. Chem. Phys. 121, 1 (2004).

[110] A. I. Krylov, J. Chem. Phys. 113, 6052 (2000).

[111] H. B. Schlegel, J. Phys. Chem. 92, 3075 (1987).

[112] W. Chen and W. B. Schlegel, J. Chem. Phys. 101, 5957 (1994).

[113] M. W. Wong and L. Radom, J. Phys. Chem. 99, 8582 (1995).

[114] D. J. Henry, C. J. Parkinson, and L. Radom, J. Phys. Chem. A 106, 7927 (2002).

[115] J. Baker, A. Scheiner, and J. Andzelm, Chem. Phys. Lett. 216, 380 (1993).

[116] T. J. Lee, J. E. Rice, G. E. Scuseria, and H. F. Schaefer, Theor. Chim. Acta 75, 81 (1989).

[117] T. J. Lee and P. R. Taylor, Int. J. Quantum Chem. Symp. 23, 199 (1989).

[118] K. Kawaguchi, T. Amano, and E. Hirato, J. Mol. Spec.. 131, 58 (1988).

[119] E. F. C. Byrd, C. D. Sherrill, and M. Head-Gordon, J. Phys. Chem. A 105, 9736 (2001).

[120] P. G. Carrick, J. Pfeiffer, E. Koester, F. K. Tittel, and J. Kasper, J. Chem. Phys. 76, 3336 (1982).

[121] F. Shokoohi, T. A. Watson, R. F. Kong, and A. R. andC. Wittig, J. Phys. Chem. 80, 5695 (1986).

[122] P. Rosmus and H.-J. Werner, J. Chem. Phys. 80, 5085 (1984). 
[123] H. Pedersen, C. Brink, L. Andersen, N. Bjerre, H. Hvelplund, D. Kella, and H. Shen, J. Chem. Phys. 109, 5849 (1998).

[124] A. Einstein, Verh. d. Deutsch. Phys. Ges. 18, 318 (1916).

[125] A. Einstein, Z. Phys. 18, 121 (1917). 


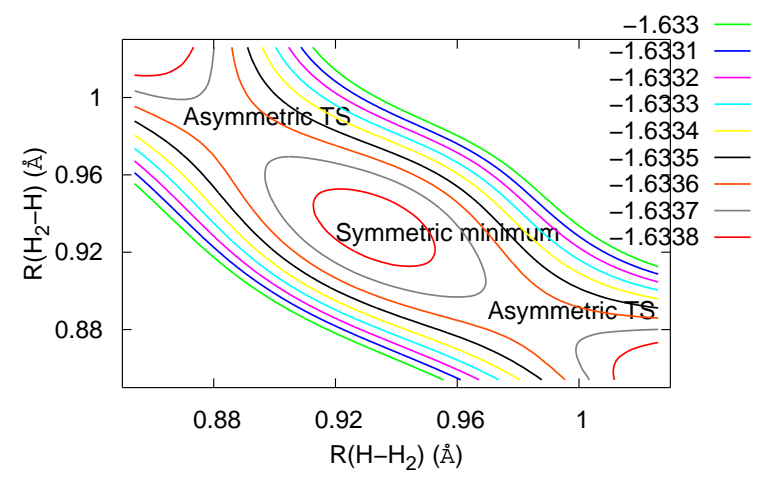

Figure 1: RMP2/cc-pVDZ Potential Energy Surface (in a.u.) for $\mathrm{H} \cdot+\mathrm{H}_{2} \rightarrow \mathrm{H}_{2}+\mathrm{H} \cdot$. 


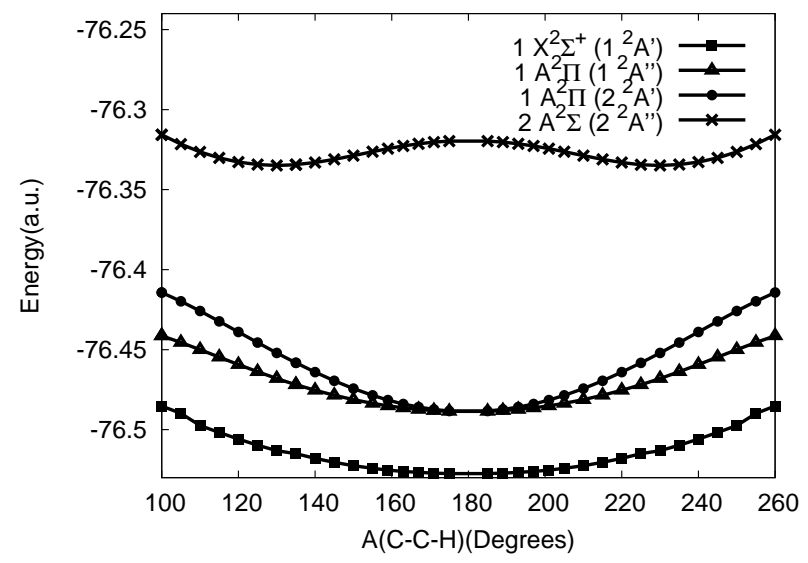

Figure 2: EOM-CCSD/cc-pVQZ bending potential for the four lowest-lying states of CCH. R(C$\mathrm{C})=1.200 \AA, \mathrm{R}(\mathrm{C}-\mathrm{H})=1.060 \AA$. 


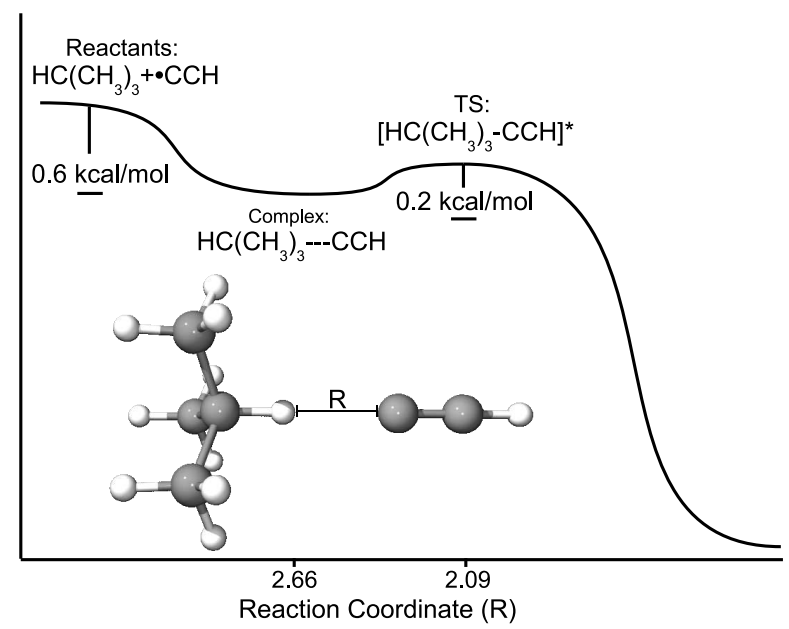

Figure 3: Schematic of the reaction of ethynyl radical with isobutane; quantities computed at the UMP2/cc-pVDZ level of theory. 


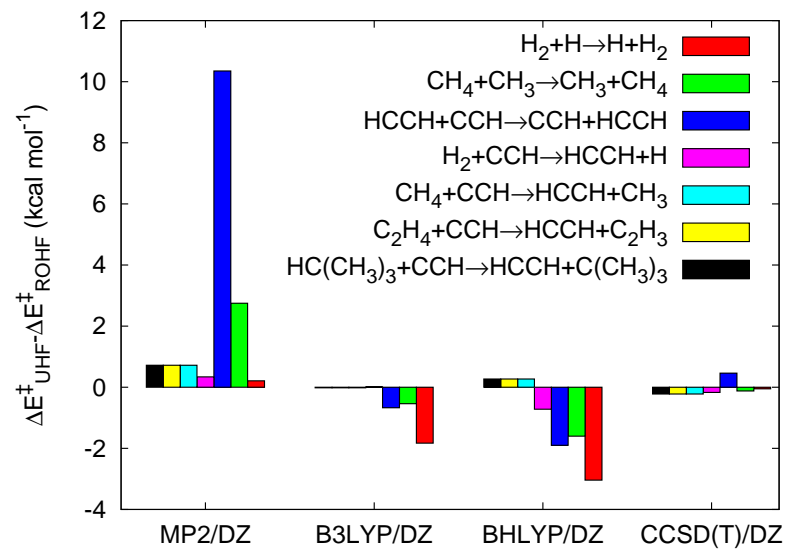

Figure 4: Effect of spin contamination on reaction barriers $\Delta E^{\ddagger}$. 


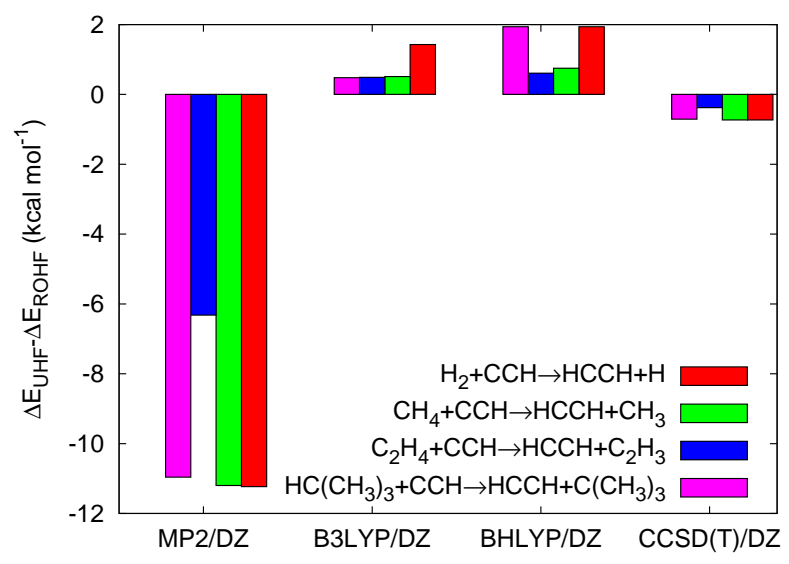

Figure 5: Effect of spin contamination on energies of reaction $\Delta E$. 


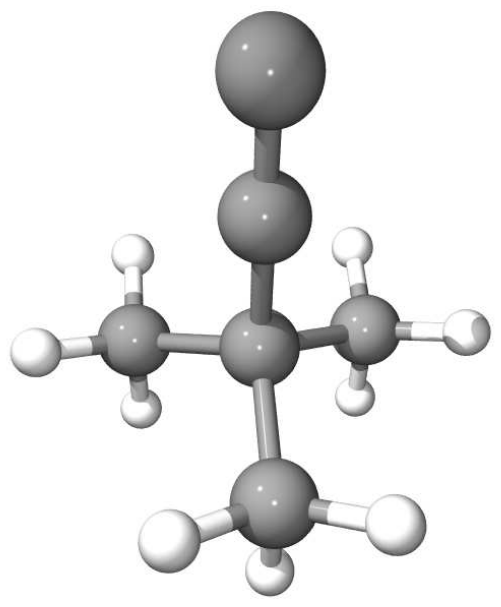

Figure 6: A generic abstraction tooltip modeled as an ethynyl radical moiety attached to a t-butyl base. 


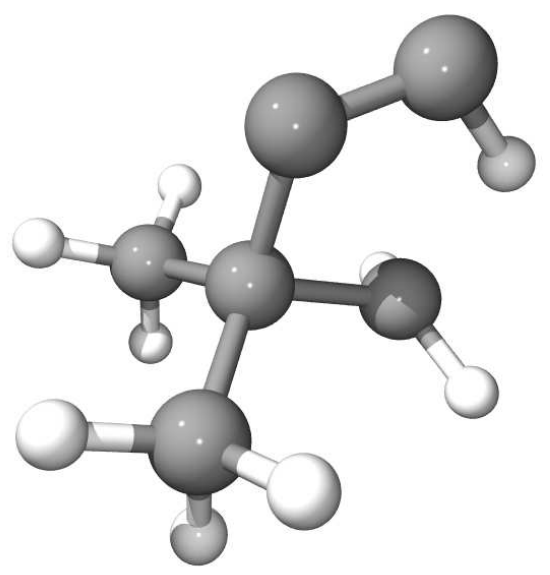

Figure 7: A transition state leading to hydrogen auto-abstraction. 


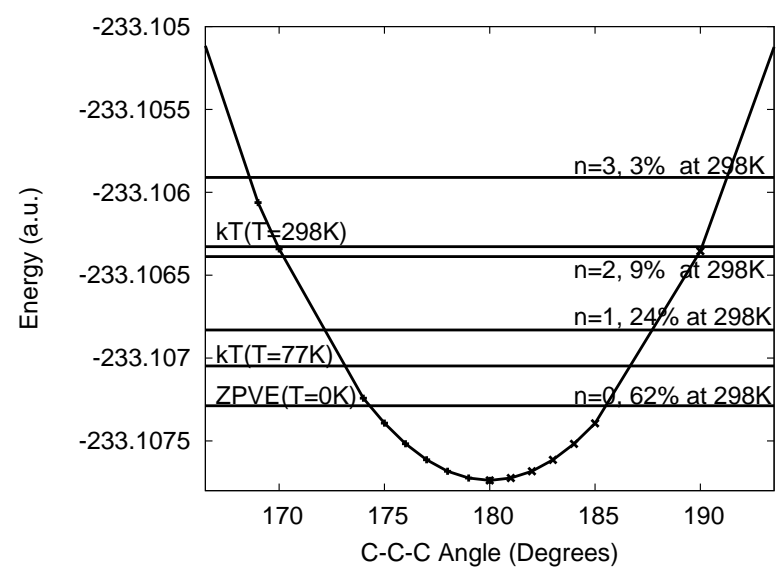

Figure 8: UMP2/cc-pVDZ -C-C-C bending potential for abstraction tooltip. All other internal coordinates of the tool were constrained to their UMP2/cc-pVDZ optimized values. The bending coordinate chosen keeps the ethynyl group co-planar with one of the $\mathrm{C}-\mathrm{C}$ bonds of the t-butyl base. 
Table 1: Nominal Transition States Having More than One Imaginary Vibrational Frequency ${ }^{a}$

\begin{tabular}{|c|c|c|c|}
\hline level of theory & Hessian index & imag. freqs & comment \\
\hline \multicolumn{4}{|c|}{$\mathrm{HCC} \cdot+\mathrm{HCCH} \rightarrow \mathrm{HCCH}+\cdot \mathrm{CCH}^{b}$} \\
\hline RMP2/DZ & 3 & $1640 \mathrm{i}, 59 \mathrm{i}, 59 \mathrm{i}$ & \multirow[t]{6}{*}{ basis set effect } \\
\hline RMP2/TZ & 1 & $1659 \mathrm{i}$ & \\
\hline RB3LYP/DZ & 3 & $1293 \mathrm{i}, 88 \mathrm{i}, 88 \mathrm{i}$ & \\
\hline RB3LYP/TZ & 3 & $1428 \mathrm{i}, 56 \mathrm{i}, 56 \mathrm{i}$ & \\
\hline UB3LYP/DZ & 3 & $1205 \mathrm{i}, 35 \mathrm{i}, 35 \mathrm{i}$ & \\
\hline UB3LYP/TZ & 3 & $1342 \mathrm{i}, 12 \mathrm{i}, 12 \mathrm{i}$ & \\
\hline \multicolumn{4}{|c|}{$\mathrm{HCC} \cdot+\mathrm{H}_{2} \rightarrow \mathrm{HCCH}+\cdot \mathrm{H}^{c}$} \\
\hline RMP2/DZ & 3 & $640 \mathrm{i}, 80 \mathrm{i}, 80 \mathrm{i}$ & \multirow[t]{2}{*}{ basis set effect } \\
\hline RMP2/TZ & 1 & $606 \mathrm{i}$ & \\
\hline $\mathrm{RCCSD}(\mathrm{T}) / \mathrm{DZ}$ & 3 & $571 \mathrm{i}, 92 \mathrm{i}, 92 \mathrm{i}$ & \multirow[t]{2}{*}{ basis set effect } \\
\hline $\mathrm{RCCSD}(\mathrm{T}) / \mathrm{TZ}$ & 1 & $527 \mathrm{i}$ & \\
\hline $\mathrm{UCCSD}(\mathrm{T}) / \mathrm{DZ}$ & 3 & $587 \mathrm{i}, 68 \mathrm{i}, 68 \mathrm{i}$ & \multirow[t]{2}{*}{ basis set effect } \\
\hline $\mathrm{UCCSD}(\mathrm{T}) / \mathrm{TZ}$ & 1 & $540 \mathrm{i}$ & \\
\hline \multicolumn{4}{|c|}{$\mathrm{HCC} \cdot+\mathrm{CH}_{4} \rightarrow \mathrm{HCCH}+\cdot \mathrm{CH}_{3}$} \\
\hline RMP2/DZ & 3 & $257 \mathrm{i}, 63 \mathrm{i}, 63 \mathrm{i}$ & \\
\hline RMP2/TZ & 3 & $224 \mathrm{i}$ & \\
\hline $\mathrm{RCCSD}(\mathrm{T}) / \mathrm{DZ}$ & 3 & $247 \mathrm{i}, 74 \mathrm{i}, 74 \mathrm{i}$ & \\
\hline UMP2/DZ & 3 & $282 \mathrm{i}, 34 \mathrm{i}, 34 \mathrm{i}$ & \multirow{5}{*}{ basis set effect } \\
\hline UMP2/TZ & 3 & $257 \mathrm{i}$ & \\
\hline $\mathrm{UCCSD}(\mathrm{T}) / \mathrm{DZ}$ & 3 & $259 \mathrm{i}, 50 \mathrm{i}, 50 \mathrm{i}$ & \\
\hline UBHLYP/DZ & 1 & $96 \mathrm{i}$ & \\
\hline UBHLYP/TZ & 1 & $140 \mathrm{i}$ & \\
\hline \multicolumn{4}{|c|}{$\mathrm{HCC} \cdot+\mathrm{C}_{2} \mathrm{H}_{4} \rightarrow \mathrm{HCCH}+\cdot \mathrm{C}_{2} \mathrm{H}_{3}$} \\
\hline RMP2/DZ & 4 & 281i,143i,51i,20i & \\
\hline $\mathrm{RMP} 2 / \mathrm{TZ}$ & 4 & $251 \mathrm{i}, 105 \mathrm{i}, 72 \mathrm{i}, 36 \mathrm{i}$ & \\
\hline $\operatorname{RCCSD}(\mathrm{T}) / \mathrm{DZ}$ & 2 & $265 \mathrm{i}, 95 \mathrm{i}, 44 \mathrm{i}$ & \\
\hline UMP2/DZ & 2 & $487 \mathrm{i}, 45 \mathrm{i}$ & \\
\hline $\mathrm{UCCSD}(\mathrm{T}) / \mathrm{DZ}$ & 2 & $291 \mathrm{i}, 65 \mathrm{i}$ & \\
\hline \multicolumn{4}{|c|}{$\mathrm{HCC} \cdot+\mathrm{HC}\left(\mathrm{CH}_{3}\right)_{3} \rightarrow \mathrm{HCCH}+\cdot \mathrm{C}\left(\mathrm{CH}_{3}\right)_{3}$} \\
\hline RMP2/DZ & 3 & $45 \mathrm{i}, 35 \mathrm{i}, 22 \mathrm{i}$ & \\
\hline UMP2/DZ & 3 & $77 \mathrm{i}, 32 \mathrm{i}, 32 \mathrm{i}$ & \\
\hline \multicolumn{4}{|c|}{$\mathrm{HCC} \cdot+\mathrm{C}_{6} \mathrm{H}_{6} \rightarrow \mathrm{HCCH}+\cdot \mathrm{C}_{6} \mathrm{H}_{5}$} \\
\hline RMP2/DZ & 3 & $190 \mathrm{i}, 113 \mathrm{i}, 45 \mathrm{i}$ & \\
\hline UMP2/DZ & 2 & $241 \mathrm{i}, 62 \mathrm{i}$ & \\
\hline
\end{tabular}

${ }^{a}$ At least in some cases, the additional imagiaary frequencies tend to disappear at more reliable levels of theory and are considered artifactual; see text. ${ }^{b}$ Only one imaginary frequency 
Table 2: Transition State Geometries $(\AA)$ of the Type $\mathrm{R}_{1}-\mathrm{H}-\mathrm{R}_{2}$, using the cc-pVDZ Basis Set $^{a}$

\begin{tabular}{|c|c|c|c|c|c|c|c|c|}
\hline \multirow[b]{2}{*}{ transition state } & \multicolumn{2}{|c|}{ MP2 } & \multicolumn{2}{|c|}{ B3LYP } & \multicolumn{2}{|c|}{ BHLYP } & \multicolumn{2}{|c|}{$\operatorname{CCSD}(\mathrm{T})$} \\
\hline & $\mathrm{R}\left(\mathrm{R}_{1}-\mathrm{H}\right)$ & $\mathrm{R}\left(\mathrm{H}-\mathrm{R}_{2}\right)$ & $\mathrm{R}\left(\mathrm{R}_{1}-\mathrm{H}\right)$ & $\mathrm{R}\left(\mathrm{H}-\mathrm{R}_{2}\right)$ & $\mathrm{R}\left(\mathrm{R}_{1}-\mathrm{H}\right)$ & $\mathrm{R}\left(\mathrm{H}-\mathrm{R}_{2}\right)$ & $\mathrm{R}\left(\mathrm{R}_{1}-\mathrm{H}\right)$ & $\mathrm{R}\left(\mathrm{H}-\mathrm{R}_{2}\right)$ \\
\hline \multicolumn{9}{|c|}{ UHF REFERENCE } \\
\hline $\mathrm{H}-\mathrm{H}-\mathrm{H}$ & 0.932 & 0.932 & 0.947 & 0.947 & 0.939 & 0.939 & 0.943 & 0.943 \\
\hline $\mathrm{CH}_{3}-\mathrm{H}-\mathrm{CH}_{3}$ & 1.330 & 1.330 & 1.350 & 1.349 & 1.340 & 1.341 & 1.344 & 1.344 \\
\hline $\mathrm{HCC}-\mathrm{H}-\mathrm{CCH}$ & 1.269 & 1.269 & 1.282 & 1.282 & 1.273 & 1.273 & 1.281 & 1.281 \\
\hline $\mathrm{H}-\mathrm{H}-\mathrm{CCH}$ & 0.783 & 1.740 & 0.762 & 2.866 & 0.767 & 1.950 & 0.793 & 1.722 \\
\hline $\mathrm{CH}_{3}-\mathrm{H}-\mathrm{CCH}$ & 1.135 & 1.724 & 1.100 & 3.504 & 1.112 & 1.907 & 1.148 & 1.678 \\
\hline $\mathrm{C}_{2} \mathrm{H}_{3}-\mathrm{H}-\mathrm{CCH}$ & 1.152 & 1.580 & & & & & 1.155 & 1.610 \\
\hline$\left(\mathrm{CH}_{3}\right)_{3} \mathrm{C}-\mathrm{H}-\mathrm{CCH}$ & 1.117 & 2.093 & & & & & 1.117 & 2.205 \\
\hline $\mathrm{C}_{6} \mathrm{H}_{5}-\mathrm{H}-\mathrm{CCH}$ & 1.145 & 1.613 & & & & & 1.150 & 1.625 \\
\hline \multicolumn{9}{|c|}{ ROHF REFERENCE } \\
\hline $\mathrm{H}-\mathrm{H}-\mathrm{H}$ & 0.984 & 0.886 & 0.942 & 0.942 & 0.930 & 0.930 & 0.943 & 0.943 \\
\hline $\mathrm{CH}_{3}-\mathrm{H}-\mathrm{CH}_{3}$ & 1.416 & 1.266 & 1.347 & 1.347 & 1.334 & 1.334 & 1.344 & 1.344 \\
\hline $\mathrm{HCC}-\mathrm{H}-\mathrm{CCH}$ & 1.392 & 1.187 & 1.280 & 1.280 & 1.269 & 1.269 & 1.282 & 1.282 \\
\hline $\mathrm{H}-\mathrm{H}-\mathrm{CCH}$ & 0.782 & 1.760 & 0.764 & 2.564 & 0.777 & 1.777 & 0.792 & 1.729 \\
\hline $\mathrm{CH}_{3}-\mathrm{H}-\mathrm{CCH}$ & 1.128 & 1.770 & & & & & 1.147 & 1.684 \\
\hline $\mathrm{C}_{2} \mathrm{H}_{3}-\mathrm{H}-\mathrm{CCH}$ & 1.129 & 1.713 & & & & & 1.151 & 1.627 \\
\hline$\left(\mathrm{CH}_{3}\right)_{3} \mathrm{C}-\mathrm{H}-\mathrm{CCH}$ & 1.112 & 2.254 & & & & & 1.117 & 2.235 \\
\hline $\mathrm{C}_{6} \mathrm{H}_{5}-\mathrm{H}-\mathrm{CCH}$ & 1.125 & 1.736 & & & & & 1.146 & 1.642 \\
\hline
\end{tabular}


Table 3: Barrier Heights $\left(\mathrm{kcal} \mathrm{mol}^{-1}\right.$ ) for Symmetric Reactions Using UHF and ROHF References.

\begin{tabular}{|c|c|c|c|c|c|c|c|c|c|c|c|c|c|}
\hline & \multicolumn{3}{|c|}{ MP2 } & \multicolumn{3}{|c|}{ B3LYP } & \multicolumn{3}{|c|}{ BHLYP } & \multicolumn{3}{|c|}{ CCSD $(\mathrm{T})$} & \multirow[b]{2}{*}{ Expt. } \\
\hline & $\overline{\mathrm{DZ}}$ & $\mathrm{TZ}$ & QZ & $\mathrm{DZ}$ & $\mathrm{TZ}$ & QZ & DZ & $\mathrm{TZ}$ & QZ & $\mathrm{DZ}$ & $\mathrm{TZ}$ & QZ & \\
\hline \multicolumn{14}{|c|}{ UHF REFERENCE } \\
\hline \multicolumn{14}{|c|}{$\mathrm{H}_{2}+\mathrm{H} \rightarrow \mathrm{H}+\mathrm{H}_{2}$} \\
\hline$\Delta E^{\ddagger}$ & 13.3 & 13.2 & 13.0 & 3.0 & 4.1 & 4.1 & 5.5 & 6.5 & 6.5 & 10.3 & 10.0 & 9.8 & \\
\hline$\Delta H^{\ddagger}(0)$ & 12.6 & 12.5 & 12.2 & 2.0 & 3.1 & 3.1 & 4.7 & 5.6 & 5.7 & 9.6 & 9.3 & 9.0 & \\
\hline$\Delta H^{\ddagger}(298)$ & 11.8 & 11.7 & 11.4 & 1.1 & 2.3 & 2.3 & 3.9 & 4.8 & 4.8 & 8.8 & 8.4 & 8.2 & \\
\hline$E_{a}(298)$ & 13.0 & 12.8 & 12.6 & 2.3 & 3.5 & 3.5 & 5.1 & 6.0 & 6.0 & 10.0 & 9.6 & 9.3 & $9.7^{a}$ \\
\hline$E_{a}(298)-\mathrm{W}$ & 12.0 & 11.9 & 11.7 & 2.1 & 3.0 & 3.1 & 4.5 & 5.4 & 5.4 & 9.2 & 8.8 & 8.5 & $9.7^{a}$ \\
\hline \multicolumn{14}{|c|}{$\mathrm{CH}_{3} \cdot+\mathrm{CH}_{4} \rightarrow \mathrm{CH}_{4}+\cdot \mathrm{CH}_{3}$} \\
\hline$\Delta E^{\ddagger}$ & 18.9 & 18.8 & & 13.7 & 17.1 & & 17.8 & 19.5 & & 18.1 & 17.8 & & \\
\hline$\Delta H^{\ddagger}(0)$ & 18.6 & 18.4 & & 13.2 & 16.6 & & 17.4 & 19.0 & & 17.7 & $17.4^{b}$ & & \\
\hline$\Delta H^{\ddagger}(298)$ & 17.9 & 17.8 & & 12.6 & 16.1 & & 16.8 & 18.5 & & 17.1 & $16.7^{b}$ & & \\
\hline $\mathrm{E}_{a}(298)$ & 19.1 & 19.0 & & 13.8 & 17.3 & & 18.0 & 19.6 & & 18.2 & $17.9^{b}$ & & $14.3^{c}$ \\
\hline$E_{a}(298)-\mathrm{W}$ & 18.1 & 18.0 & & 13.0 & 16.4 & & 17.0 & 18.7 & & 17.3 & $17.0^{b}$ & & $14.3^{c}$ \\
\hline \multicolumn{14}{|c|}{$\mathrm{HCC} \cdot+\mathrm{HCCH} \rightarrow \mathrm{HCCH}+\cdot \mathrm{CCH}$} \\
\hline$\Delta E^{\ddagger}$ & 20.2 & 17.0 & & 7.4 & 11.3 & & 11.8 & 13.3 & & 13.1 & 11.7 & & \\
\hline$\Delta H^{\ddagger}(0)$ & 20.2 & 17.1 & & 5.0 & 8.2 & & 8.7 & 10.2 & & 10.5 & $9.1^{b}$ & & \\
\hline$\Delta H^{\ddagger}(298)$ & 20.2 & 17.0 & & 4.8 & 7.4 & & 8.9 & 10.4 & & 10.6 & $9.3^{b}$ & & \\
\hline$E_{a}(298)$ & 21.4 & 18.2 & & 5.9 & 8.6 & & 10.1 & 11.6 & & 11.8 & $10.4^{b}$ & & $\mathrm{~N} / \mathrm{A}$ \\
\hline$E_{a}(298)-\mathrm{W}$ & 20.4 & 17.2 & & 5.2 & 7.8 & & 9.3 & 10.7 & & 11.0 & $9.6^{b}$ & & $\mathrm{~N} / \mathrm{A}$ \\
\hline \multicolumn{14}{|c|}{ ROHF REFERENCE } \\
\hline $\mathrm{H}_{2}+\mathrm{H} \rightarrow \mathrm{H}+$ & & & & & & & & & & & & & \\
\hline$\Delta E^{\ddagger}$ & 13.1 & 12.8 & 12.5 & 4.8 & 5.9 & 5.9 & 8.5 & 9.4 & 9.5 & 10.4 & 10.1 & 9.8 & \\
\hline$\Delta H^{\ddagger}(0)$ & 12.5 & 12.1 & 11.8 & 3.8 & 4.9 & 5.0 & 7.8 & 8.7 & 8.7 & 9.7 & 9.3 & 9.0 & \\
\hline$\Delta H^{\ddagger}(298)$ & 11.7 & 11.3 & 11.0 & 3.0 & 4.1 & 4.1 & 7.0 & 7.8 & 7.9 & 8.9 & 8.5 & 8.2 & \\
\hline$E_{a}(298)$ & 12.9 & 12.5 & 12.2 & 4.2 & 5.3 & 5.3 & 8.2 & 9.0 & 9.1 & 10.0 & 9.7 & 9.5 & $9.7^{a}$ \\
\hline$E_{a}(298)-\mathrm{W}$ & 11.9 & 11.5 & 11.2 & 3.6 & 4.6 & 4.6 & 7.3 & 9.9 & 8.2 & 9.2 & 8.9 & 8.6 & $9.7^{a}$ \\
\hline \multicolumn{14}{|c|}{$\mathrm{CH}_{3} \cdot+\mathrm{CH}_{4} \rightarrow \mathrm{CH}_{4}+\cdot \mathrm{CH}_{3}$} \\
\hline$\Delta E^{\ddagger}$ & 16.1 & 15.9 & & 14.2 & 16.1 & & 19.4 & 21.1 & & 18.2 & 17.9 & & \\
\hline$\Delta H^{\ddagger}(0)$ & 15.7 & 15.4 & & 13.8 & 15.6 & & 19.1 & 20.8 & & 17.8 & $17.5^{b}$ & & \\
\hline$\Delta H^{\ddagger}(298)$ & 15.0 & 14.8 & & 13.2 & 15.1 & & 18.5 & 20.1 & & 17.2 & $16.9^{b}$ & & \\
\hline$E_{a}(298)$ & 16.2 & 16.0 & & 14.4 & 16.2 & & 19.6 & 21.3 & & 18.4 & $18.1^{b}$ & & $14.3^{c}$ \\
\hline$E_{a}(298)-\mathrm{W}$ & 15.3 & 15.1 & & 13.5 & 15.4 & & 18.7 & 20.3 & & 17.5 & $17.2^{b}$ & & $14.3^{c}$ \\
\hline \multicolumn{14}{|c|}{$\mathrm{HCC} \cdot+\mathrm{HCCH} \rightarrow \mathrm{HCCH}+\cdot \mathrm{CCH}$} \\
\hline$\Delta E^{\ddagger}$ & 9.9 & 8.7 & & 8.1 & 9.8 & & 13.7 & 15.2 & & 12.6 & 11.5 & & \\
\hline$\Delta H^{\ddagger}(0)$ & 7.1 & 6.1 & & 5.6 & 7.6 & & 10.8 & 12.2 & & 10.2 & $9.0^{b}$ & & \\
\hline$\Delta H^{\ddagger}(298)$ & 6.1 & 6.2 & & 5.4 & 7.3 & & 11.0 & 12.5 & & 10.1 & $8.9^{b}$ & & \\
\hline $\mathrm{E}_{a}(298)$ & 7.3 & 7.4 & & 6.6 & 8.5 & & 12.2 & 13.6 & & 11.3 & $10.1^{b}$ & & $\mathrm{~N} / \mathrm{A}$ \\
\hline$E_{a}(298)-\mathrm{W}$ & 6.5 & 6.6 & & 7.1 & 7.9 & & 11.3 & 12.7 & & 10.7 & $9.5^{b}$ & & $\mathrm{~N} / \mathrm{A}$ \\
\hline
\end{tabular}

${ }^{a}$ Ref. 68. ${ }^{b} \Delta$ ZPVE, thermal, and Wigner tunneling corrections evaluated at $\operatorname{CCSD}(\mathrm{T}) / \mathrm{cc}-\mathrm{pVDZ}$ level. ${ }^{c}$ Ref. 69. 
Table 4: Thermodynamic Quantities $\left(\mathrm{kcal} \mathrm{mol}^{-1}\right)$ for Non-symmetric Reactions using UHF References. $^{a}$

\begin{tabular}{|c|c|c|c|c|c|c|c|c|c|}
\hline & \multicolumn{2}{|c|}{ MP2 } & \multicolumn{2}{|c|}{ B3LYP } & \multicolumn{2}{|c|}{ BHLYP } & \multicolumn{2}{|c|}{$\operatorname{CCSD}(\mathrm{T})$} & \multirow[b]{2}{*}{ expt } \\
\hline & DZ & $\mathrm{TZ}$ & $\mathrm{DZ}$ & $\mathrm{TZ}$ & $\mathrm{DZ}$ & $\mathrm{TZ}$ & $\mathrm{DZ}$ & $\mathrm{TZ}$ & \\
\hline \multicolumn{10}{|c|}{$\mathrm{HCC} \cdot+\mathrm{H}_{2} \rightarrow \mathrm{HCCH}+\cdot \mathrm{H}$} \\
\hline$\Delta E^{\ddagger}$ & 3.5 & 2.5 & - & - & 0.6 & 1.0 & 3.4 & 2.0 & \\
\hline$\Delta H^{\ddagger}(0)$ & 3.8 & 3.3 & - & - & 1.0 & 1.5 & 3.7 & 3.0 & \\
\hline$\Delta H^{\ddagger}(298)$ & 3.7 & 2.9 & - & - & 1.2 & 1.4 & 2.4 & 2.6 & \\
\hline$E_{a}(298)$ & 4.9 & 4.1 & - & - & 2.4 & 2.6 & 3.6 & 3.8 & $2.0^{b}$ \\
\hline$E_{a}(298)-\mathrm{W}$ & 4.5 & 3.8 & - & - & 2.3 & 2.5 & 3.3 & 3.5 & $2.0^{b}$ \\
\hline$\Delta E$ & -46.7 & -46.8 & -30.7 & -30.0 & -31.4 & -30.8 & -29.4 & -31.5 & \\
\hline$\Delta H(0)$ & -47.5 & -47.6 & -28.3 & -28.4 & -29.9 & -29.5 & -28.0 & -30.4 & \\
\hline$\Delta H(298)$ & -47.8 & -48.0 & -28.6 & -29.3 & -30.5 & -30.1 & -28.7 & -31.0 & $-28.9^{c}$ \\
\hline \multicolumn{10}{|c|}{$\mathrm{HCC} \cdot+\mathrm{CH}_{4} \rightarrow \mathrm{HCCH}+\cdot \mathrm{CH}_{3}$} \\
\hline$\Delta E^{\ddagger}$ & 2.6 & 1.4 & - & - & 0.3 & 0.8 & 2.4 & & \\
\hline$\Delta H^{\ddagger}(0)$ & 1.6 & 1.0 & - & - & 0.3 & 0.5 & 1.7 & & \\
\hline$\Delta H^{\ddagger}(298)$ & 1.4 & 1.1 & - & - & 0.5 & 0.7 & 1.8 & & \\
\hline$E_{a}(298)$ & 2.6 & 2.3 & - & - & 1.7 & 1.9 & 2.9 & & $1.0^{d}$ \\
\hline$E_{a}(298)-\mathrm{W}$ & 2.5 & 2.2 & - & - & 1.7 & 1.8 & 2.9 & & $1.0^{d}$ \\
\hline$\Delta E$ & -37.9 & -39.1 & -27.8 & -29.1 & -28.6 & -29.9 & -24.8 & $-27.8^{e}$ & \\
\hline$\Delta H(0)$ & -41.9 & -43.0 & -28.3 & -30.4 & -30.4 & -31.9 & -26.8 & $-29.8^{e}$ & \\
\hline$\Delta H(298)$ & -41.5 & -42.6 & -27.8 & -30.5 & -30.3 & -31.7 & -26.7 & $-29.8^{e}$ & $-28.2^{c}$ \\
\hline \multicolumn{10}{|c|}{$\mathrm{HCC} \cdot+\mathrm{C}_{2} \mathrm{H}_{4} \rightarrow \mathrm{HCCH}+\cdot \mathrm{C}_{2} \mathrm{H}_{3}$} \\
\hline$\Delta E^{\ddagger}$ & 6.0 & 3.5 & - & - & 0.9 & 1.6 & 3.1 & & \\
\hline$\Delta H^{\ddagger}(0)$ & 5.7 & $3.2^{f}$ & - & - & 0.1 & 0.4 & 1.7 & & \\
\hline$\Delta H^{\ddagger}(298)$ & 6.1 & $3.6^{f}$ & - & - & 0.4 & 0.6 & 1.5 & & \\
\hline$E_{a}(298)$ & 7.2 & $4.8^{f}$ & - & - & 1.6 & 1.8 & 2.6 & & $\mathrm{~N} / \mathrm{A}$ \\
\hline$E_{a}(298)-\mathrm{W}$ & 7.0 & $4.6^{f}$ & - & - & 1.6 & 1.8 & 2.6 & & $\mathrm{~N} / \mathrm{A}$ \\
\hline$\Delta E$ & -26.8 & -28.2 & -23.3 & -24.4 & -23.0 & -23.9 & -19.2 & -21.8 & \\
\hline$\Delta H(0)$ & -29.4 & -30.8 & -23.5 & -25.4 & -24.4 & -25.5 & -20.4 & -23.5 & \\
\hline$\Delta H(298)$ & -29.1 & -30.5 & -23.2 & -25.6 & -24.3 & -25.4 & -20.6 & -23.4 & $-21.8^{c}$ \\
\hline \multicolumn{10}{|c|}{$\mathrm{HCC} \cdot+\mathrm{HC}\left(\mathrm{CH}_{3}\right)_{3} \rightarrow \mathrm{HCCH}+\cdot \mathrm{C}\left(\mathrm{CH}_{3}\right)_{3}$} \\
\hline$\Delta E^{\ddagger}$ & -0.4 & 0.0 & - & - & - & - & -0.6 & & \\
\hline$\Delta H^{\ddagger}(0)$ & -0.7 & $-0.4^{f}$ & - & - & - & - & $-1.0^{f}$ & & \\
\hline$\Delta H^{\ddagger}(298)$ & -1.1 & $-0.7^{f}$ & - & - & - & - & $-1.3^{f}$ & & \\
\hline$E_{a}(298)$ & 0.1 & $0.5^{f}$ & - & - & - & - & $-0.2^{f}$ & & $-0.1^{h}$ \\
\hline$E_{a}(298)-\mathrm{W}$ & 0.1 & $0.4^{f}$ & - & - & - & - & $-0.2^{f}$ & & $-0.1^{h}$ \\
\hline$\Delta E$ & -44.5 & -45.5 & -39.3 & -40.7 & -37.1 & -39.7 & -32.3 & & \\
\hline$\Delta H(0)$ & -48.1 & $-49.1^{f}$ & -39.9 & $-41.2^{g}$ & -38.9 & $-41.5^{g}$ & $-35.9^{f}$ & & \\
\hline$\Delta H(298)$ & -47.5 & $-48.5^{f}$ & -39.1 & $-40.5^{g}$ & -38.4 & $-41.1^{g}$ & $-35.2^{f}$ & & $-36.6^{c}$ \\
\hline \multicolumn{10}{|c|}{$\mathrm{HCC} \cdot+\mathrm{C}_{6} \mathrm{H}_{6} \rightarrow \mathrm{HCCH}+\cdot \mathrm{C}_{6} \mathrm{H}_{5}$} \\
\hline$\Delta E^{\ddagger}$ & 3.1 & 1.6 & - & - & - & - & 2.3 & & \\
\hline$\Delta H^{\ddagger}(0)$ & 1.1 & $-0.4^{f}$ & - & - & - & - & $0.2^{f}$ & & \\
\hline$\Delta H^{\ddagger}(298)$ & 1.2 & $-0.3^{f}$ & - & - & - & - & $0.4^{f}$ & & \\
\hline$E_{a}(298)$ & 2.4 & $0.9^{f}$ & - & - & - & - & $1.6^{f}$ & & $0^{i}$ \\
\hline$E_{a}(298)-\mathrm{W}$ & 2.3 & $0.8^{f}$ & - & - & - & - & $1.5^{f}$ & & $0^{i}$ \\
\hline$\Delta E$ & -7.7 & -11.0 & -21.8 & -23.0 & -21.0 & -22.1 & -15.8 & & \\
\hline$\Delta H(0)$ & -7.3 & $-10.6^{f}$ & -21.2 & $-22.4^{g}$ & -21.6 & $-22.7^{g}$ & $-15.4^{f}$ & & \\
\hline$\Delta H(298)$ & -7.3 & $-10.7^{f}$ & -20.9 & $-22.1^{g}$ & -21.6 & $-22.7^{g}$ & $-15.5^{f}$ & & $-21.9^{c}$ \\
\hline
\end{tabular}

a "-" indicates the absence of a transition state (barrier) corresponding to a collinear hydrogen abstraction. ${ }^{b}$ Ref. $70 .{ }^{c}$ Ref. 66. ${ }^{d}$ Ref. 71. ${ }^{e} \Delta \mathrm{ZPVE}$, thermal, and Wigner tunneling corrections evaluated at $\operatorname{UCCSD}(\mathrm{T}) / \mathrm{cc}-\mathrm{pVDZ}$ level. ${ }^{f} \triangle \mathrm{ZPVE}$, thermal, and Wigner tunneling corrections evaluated at UMP2/cc-pVDZ level. ${ }^{g} \triangle \mathrm{ZPVE}$ and thermal corrections evaluated using the cc-pVDZ basis set. ${ }^{h}$ Ref. 72 . 
Table 5: Thermodynamic Quantities $\left(\mathrm{kcal} \mathrm{mol}^{-1}\right)$ for Non-symmetric Reactions using ROHF References. ${ }^{a}$

\begin{tabular}{|c|c|c|c|c|c|c|c|c|c|}
\hline & \multicolumn{2}{|c|}{ MP2 } & \multicolumn{2}{|c|}{ B3LYP } & \multicolumn{2}{|c|}{ BHLYP } & \multicolumn{2}{|c|}{$\operatorname{CCSD}(\mathrm{T})$} & \multirow[b]{2}{*}{ expt } \\
\hline & DZ & $\mathrm{TZ}$ & DZ & $\mathrm{TZ}$ & DZ & $\mathrm{TZ}$ & DZ & $\mathrm{TZ}$ & \\
\hline \multicolumn{10}{|c|}{$\mathrm{HCC} \cdot+\mathrm{H}_{2} \rightarrow \mathrm{HCCH}+\cdot \mathrm{H}$} \\
\hline$\Delta E^{\ddagger}$ & 3.2 & 2.1 & - & - & 1.4 & 1.8 & 3.5 & 2.3 & \\
\hline$\Delta H^{\ddagger}(0)$ & 3.8 & 3.1 & - & - & 2.0 & 2.4 & 4.3 & 3.3 & \\
\hline$\Delta H^{\ddagger}(298)$ & 2.3 & 2.7 & - & - & 1.9 & 2.2 & 2.7 & 2.9 & \\
\hline$E_{a}(298)$ & 3.5 & 3.9 & - & - & 3.1 & 3.4 & 3.9 & 4.0 & $2.0^{b}$ \\
\hline$E_{a}(298)-\mathrm{W}$ & 3.2 & 3.6 & - & - & 2.9 & 3.2 & 3.6 & 3.8 & $2.0^{b}$ \\
\hline$\Delta E$ & -35.5 & -36.9 & -32.1 & -31.4 & -33.3 & -32.8 & -28.6 & -30.9 & \\
\hline$\Delta H(0)$ & -33.6 & -35.7 & -29.8 & -29.0 & -31.7 & -31.4 & -26.6 & -29.5 & \\
\hline$\Delta H(298)$ & -34.6 & -36.4 & -30.1 & -29.3 & -32.4 & -32.0 & -27.7 & -30.2 & $-28.9^{c}$ \\
\hline \multicolumn{10}{|c|}{$\mathrm{HCC} \cdot+\mathrm{CH}_{4} \rightarrow \mathrm{HCCH}+\cdot \mathrm{CH}_{3}$} \\
\hline$\Delta E^{\ddagger}$ & 1.8 & 0.7 & - & - & 1.0 & 1.6 & 2.6 & 2.2 & \\
\hline$\Delta H^{\ddagger}(0)$ & 1.5 & 0.4 & - & - & 1.0 & 1.2 & 2.2 & $1.7^{d}$ & \\
\hline$\Delta H^{\ddagger}(298)$ & 0.5 & -0.6 & - & - & 1.3 & 1.5 & 0.9 & $0.5^{d}$ & \\
\hline$E_{a}(298)$ & 1.7 & 0.6 & - & - & 2.5 & 2.6 & 2.1 & $1.7^{d}$ & $1.0^{e}$ \\
\hline$E_{a}(298)-\mathrm{W}$ & 1.6 & 0.5 & - & - & 2.4 & 2.6 & 2.0 & $1.6^{d}$ & $1.0^{e}$ \\
\hline$\Delta E$ & -26.7 & -29.5 & -28.3 & -29.5 & -29.3 & -30.6 & -24.1 & -27.2 & \\
\hline$\Delta H(0)$ & -28.0 & -31.2 & -28.8 & -30.0 & -31.1 & -32.5 & -25.4 & -29.0 & \\
\hline$\Delta H(298)$ & -28.3 & -31.2 & -28.4 & -29.6 & -31.0 & -32.3 & -25.8 & -29.0 & $-28.2^{c}$ \\
\hline \multicolumn{10}{|c|}{$\mathrm{HCC} \cdot+\mathrm{C}_{2} \mathrm{H}_{4} \rightarrow \mathrm{HCCH}+\cdot \mathrm{C}_{2} \mathrm{H}_{3}$} \\
\hline$\Delta E^{\ddagger}$ & 2.3 & 1.0 & - & - & 1.9 & 2.7 & 2.7 & & \\
\hline$\Delta H^{\ddagger}(0)$ & 1.3 & $-0.1^{f}$ & - & - & 0.7 & 1.1 & 1.7 & & \\
\hline$\Delta H^{\ddagger}(298)$ & -0.1 & $-1.4^{f}$ & - & - & 0.9 & 1.3 & 0.5 & & \\
\hline$E_{a}(298)$ & 1.1 & $-0.2^{f}$ & - & - & 2.1 & 2.5 & 1.7 & & $\mathrm{~N} / \mathrm{A}$ \\
\hline$E_{a}(298)-\mathrm{W}$ & 1.0 & $-0.3^{f}$ & - & - & 2.0 & 2.5 & 1.7 & & $\mathrm{~N} / \mathrm{A}$ \\
\hline$\Delta E$ & -20.5 & -22.7 & -23.8 & -24.8 & -23.6 & -24.5 & -18.8 & -21.5 & \\
\hline$\Delta H(0)$ & -21.2 & -24.7 & -24.0 & -24.8 & -24.7 & -25.8 & -19.5 & -22.6 & \\
\hline$\Delta H(298)$ & -21.6 & -24.5 & -23.6 & -24.5 & -24.8 & -25.8 & -20.0 & -22.7 & $-21.8^{c}$ \\
\hline \multicolumn{10}{|c|}{$\mathrm{HCC} \cdot+\mathrm{HC}\left(\mathrm{CH}_{3}\right)_{3} \rightarrow \mathrm{HCCH}+\cdot \mathrm{C}\left(\mathrm{CH}_{3}\right)_{3}$} \\
\hline$\Delta E^{\ddagger}$ & -0.8 & & - & - & - & - & -0.4 & & \\
\hline$\Delta H^{\ddagger}(0)$ & -0.8 & & - & - & - & - & $-0.4^{f}$ & & \\
\hline$\Delta H^{\ddagger}(298)$ & -1.3 & & - & - & - & - & $-0.9^{f}$ & & \\
\hline$E_{a}(298)$ & -0.1 & & - & - & - & - & $0.3^{f}$ & & $-0.1^{h}$ \\
\hline$E_{a}(298)-\mathrm{W}$ & -0.2 & & - & - & - & - & $0.2^{f}$ & & $-0.1^{h}$ \\
\hline$\Delta E$ & -33.6 & -36.2 & -39.8 & -41.1 & -39.0 & -40.2 & -31.5 & & \\
\hline$\Delta H(0)$ & -34.7 & $-37.3^{f}$ & -40.3 & $-41.6^{g}$ & -40.5 & $-41.7^{g}$ & $-32.6^{f}$ & & \\
\hline$\Delta H(298)$ & -34.7 & $-37.3^{f}$ & -39.6 & $-40.9^{g}$ & -40.2 & $-41.3^{g}$ & $-32.6^{f}$ & & $-36.6^{c}$ \\
\hline \multicolumn{10}{|c|}{$\mathrm{HCC} \cdot+\mathrm{C}_{6} \mathrm{H}_{6} \rightarrow \mathrm{HCCH}+\cdot \mathrm{C}_{6} \mathrm{H}_{5}$} \\
\hline$\Delta E^{\ddagger}$ & 1.6 & 0.0 & - & - & - & - & 2.0 & & \\
\hline$\Delta H^{\ddagger}(0)$ & 0.7 & $-0.9^{f}$ & - & - & - & - & $1.1^{f}$ & & \\
\hline$\Delta H^{\ddagger}(298)$ & -0.1 & $-1.6^{f}$ & - & - & - & - & $0.4^{f}$ & & \\
\hline $\mathrm{E}_{a}(298)$ & 1.1 & $-0.4^{f}$ & - & - & - & - & $1.6^{f}$ & & $0^{i}$ \\
\hline $\mathrm{E}_{a}(298)-\mathrm{W}$ & 1.0 & $-0.5^{f}$ & - & - & - & - & $1.5^{f}$ & & $0^{i}$ \\
\hline$\Delta E$ & -18.7 & -20.8 & -22.4 & -23.6 & -21.9 & -22.8 & -17.4 & & \\
\hline$\Delta H(0)$ & -18.8 & $-20.9^{f}$ & -21.8 & $-22.9^{g}$ & -22.2 & $-23.2^{g}$ & $-17.5^{f}$ & & \\
\hline$\Delta H(298)$ & -17.7 & $-19.9^{f}$ & -22.1 & $-23.2^{g}$ & -22.2 & $-23.1^{g}$ & $-16.5^{f}$ & & $-21.9^{c}$ \\
\hline
\end{tabular}

$a$ "_" indicates the absence of a transition state (barrier) corresponding to a collinear hydrogen abstraction. ${ }^{b}$ Ref. $70 .{ }^{c}$ Ref. 66. ${ }^{d} \triangle \mathrm{ZPVE}$, thermal, and Wigner tunneling corrections evaluated at RCCSD $(\mathrm{T}) / \mathrm{cc}-\mathrm{pVDZ}$ level. ${ }^{e}$ Ref. $71 .{ }^{f} \triangle \mathrm{ZPVE}$, thermal, and Wigner tunneling corrections evaluated at RMP2/cc-pVDZ level. ${ }^{g} \triangle \mathrm{ZPVE}$ and thermal corrections evaluated using the cc-pVDZ basis set. ${ }^{h}$ Ref. $72 .{ }^{i}$ Ref. 108. 
Table 6: $<\hat{S}^{2}>$ for Selected Species using a cc-pVDZ Basis $\operatorname{Set}^{a}$

\begin{tabular}{lrccc}
\hline & UMP2 & UB3LYP & UBHLYP & UCCSD(T) \\
\hline Reactants and Products & & & \\
$\cdot \mathrm{CH}_{3}$ & 0.76 & 0.75 & 0.76 & 0.75 \\
$\cdot \mathrm{CCH}$ & 1.04 & 0.77 & 0.79 & 0.75 \\
$\mathrm{C}_{2} \mathrm{H}_{3}$ & 0.91 & 0.76 & 0.78 & 0.75 \\
$\mathrm{C}\left(\mathrm{CH}_{3}\right)_{3}$ & 0.76 & 0.75 & 0.76 & 0.75 \\
$\cdot \mathrm{C}_{6} \mathrm{H}_{5}$ & 1.21 & 0.76 & 0.77 & 0.74 \\
Transition States & & & & \\
$\mathrm{H}-\mathrm{H}-\mathrm{H}$ & 0.78 & 0.76 & 0.77 & 0.75 \\
$\mathrm{CH}_{3}-\mathrm{H}-\mathrm{CH}_{3}$ & 0.78 & 0.76 & 0.76 & 0.75 \\
$\mathrm{HCC}-\mathrm{H}-\mathrm{CCH}$ & 1.13 & 0.77 & 0.80 & 0.75 \\
$\mathrm{H}-\mathrm{H}-\mathrm{CCH}$ & 1.04 & & 0.79 & 0.75 \\
$\mathrm{CH}_{3}-\mathrm{H}-\mathrm{CCH}$ & 1.03 & & 0.75 & 0.75 \\
$\mathrm{C}_{2} \mathrm{H}_{3}-\mathrm{H}-\mathrm{CCH}$ & 1.08 & & & 0.75 \\
$\mathrm{C}(\mathrm{CH})_{3}-\mathrm{H}-\mathrm{CCH}$ & 1.04 & & & 0.75 \\
$\mathrm{C}_{6} \mathrm{H}_{5}-\mathrm{H}-\mathrm{CCH}$ & 1.04 & & & 0.75
\end{tabular}

${ }^{a}$ For a doublet state, $<S^{2}>$ should be 0.75 .

Table 7: Effect of Higher-order Electron Correlation beyond RCCSD(T) on Barrier Heights, $\Delta E^{\ddagger}$, and Reaction Energies, $\Delta E\left(\mathrm{kcal} \mathrm{mol}^{-1}\right)^{a}$

\begin{tabular}{|c|c|c|c|}
\hline \multicolumn{3}{|c|}{$\overline{\mathrm{RCCSD}}(\mathrm{T}) / 6-31 \mathrm{G} \quad \mathrm{FCI}^{b} / 6-31 \mathrm{G}$} & FCI-RCCSD $(\mathrm{T})$ \\
\hline \multicolumn{4}{|c|}{$\mathrm{H}_{2}+\mathrm{H} \cdot \rightarrow \mathrm{H} \cdot+\mathrm{H}_{2}$} \\
\hline$\Delta E^{\ddagger}$ & 14.83 & 14.80 & -0.03 \\
\hline \multicolumn{4}{|c|}{$\mathrm{HCC} \cdot+\mathrm{H}_{2} \rightarrow \mathrm{HCCH}+\cdot \mathrm{H}$} \\
\hline$\Delta E^{\ddagger}$ & 5.99 & 6.02 & 0.03 \\
\hline$\Delta E$ & -26.19 & -25.94 & 0.25 \\
\hline \multicolumn{4}{|c|}{$\mathrm{H} \cdot+\mathrm{CH}_{4} \rightarrow \mathrm{H}_{2}+\cdot \mathrm{CH}_{3}$} \\
\hline$\Delta E$ & -43.68 & -43.87 & -0.20 \\
\hline
\end{tabular}

${ }^{a}$ The core 1s orbitals on carbon are frozen for correlated calculations. ${ }^{b}$ Full configuration interaction (FCI) constitutes an exact treatment of electron correlation within a given basis set. 
Table 8: Comparison of $\mathrm{UCCSD}(\mathrm{T})$ Vertical $\left(\mathrm{T}_{v}\right)$ and Adiabatic $\left(\mathrm{T}_{e}\right)$ Excitation Energies (in eV) for Lowest-Lying Excited States

\begin{tabular}{llllllllll}
\hline basis & $\cdot \mathrm{CCH}$ & $\mathrm{T}_{v}$ & $\mathrm{~T}_{e}$ & $\cdot \mathrm{CCCH}_{3}$ & $\mathrm{~T}_{v}$ & $\mathrm{~T}_{e}$ & $\cdot \mathrm{CCC}\left(\mathrm{CH}_{3}\right)_{3}$ & $\mathrm{~T}_{v}$ & $\mathrm{~T}_{e}$ \\
\hline cc-pVDZ & $1^{2} \Pi$ & 0.62 & 0.35 & $1^{2} \mathrm{E}$ & 0.46 & 0.20 & $1{ }^{2} \mathrm{E}$ & 0.46 & 0.20 \\
cc-pVTZ & $1^{2} \Pi$ & 0.70 & 0.43 & $1^{2} \mathrm{E}$ & 0.51 & 0.26 & & &
\end{tabular}

